Article

\title{
An Improved Revenue Distribution Model for Logistics Service Supply Chain Considering Fairness Preference
}

\author{
Fuqiang Lu ${ }^{1}$, Liying Wang ${ }^{2}$, Hualing $\mathrm{Bi}^{1, *}$, Zichao $\mathrm{Du}^{2}$ and Suxin Wang ${ }^{2}$ \\ 1 School of Economics and Management, Yanshan University, Qinhuangdao 066004, China; fqlu@ysu.edu.cn \\ 2 College of Information Science and Engineering, Northeastern University, Shenyang 810819, China; \\ silence2727@126.com (L.W.); duzichao_neu_edu@163.com (Z.D.);wsx96@126.com (S.W.) \\ * Correspondence: hlbi@ysu.edu.cn
}

Citation: Lu, F.; Wang, L.; Bi, H.; Du, Z.; Wang, S. An Improved Revenue Distribution Model for Logistics Service Supply Chain Considering Fairness Preference. Sustainability 2021, 13, 6711. https://doi.org/ $10.3390 /$ su13126711

Academic Editors: Tsu-Ming Yeh, Hsin-Hung $\mathrm{Wu}$, Yuh-Wen Chen and Fan-Yun Pai

Received: 17 May 2021

Accepted: 7 June 2021

Published: 13 June 2021

Publisher's Note: MDPI stays neutral with regard to jurisdictional claims in published maps and institutional affiliations.

Copyright: (c) 2021 by the authors. Licensee MDPI, Basel, Switzerland. This article is an open access article distributed under the terms and conditions of the Creative Commons Attribution (CC BY) license (https:// creativecommons.org/licenses/by/ $4.0 /)$.
Abstract: Revenue distribution is an important issue in the operations of a logistics service supply chain (LSSC). The existing works on revenue distribution are mostly based on the assumption of rational economic people that are purely self-interested. However, people also have a fairness preference, which impacts people's decision-making behavior or even the success operations of the LSSC. For a two-level supply chain consisting of logistics service integrator (LSI) and several functional logistics service providers (FLSP), this paper establishes an improved revenue distribution model considering FLSPs' inequity aversion. Specifically, the BO model (abbreviation of a model proposed by Bolton and Ockenfels in 2000) is improved to describe the FLSPs' inequity aversion, which is combined into the conventional revenue distribution model. The proposed model aims to maximize the revenue of logistics service supply chain and obtains the best revenue distribution ratio of each member under equilibrium. In the numerical cases, the impacts of inequity aversion and the number of members with inequity aversion on the revenue distribution are discussed, respectively. The results show that a higher degree of FLSP's advantageous inequity aversion corresponds to a lower revenue distribution ratio; a higher degree of FLSP's disadvantageous inequity aversion corresponds to a higher revenue distribution ratio. Increasing the number of FLSP members with inequity aversion results in a higher profit of LSI and lower total utility of FLSPs and the utility of the supply chain. The more FLSP members with inequity aversion there are, the higher the LSI's profit is, and the lower the total utility of FLSPs and the utility of supply chain are. In addition, the revenue distribution ratio of the FLSP increases with its relative fairness revenue coefficient among FLSPs.

Keywords: fairness preference; revenue distribution model; logistics service supply chain; behavioral operation

\section{Introduction}

With the diversification and dynamic demand of logistics services, the company's own logistics department or the simple cooperation with logistics companies cannot meet the needs of some customers, while enterprises are faced with the provision of high-quality services and low service costs. Under this pressure, the original logistics service outsourcing model of the enterprise gradually changed to the general contracting mode of logistics service, and the logistics service supply chain (LSSC) led by the logistics service integrator (LSI) appeared, which can provide customers with integrated logistics services [1,2].

The LSSC is usually composed of one LSI and a number of functional logistics service providers (FLSPs). The LSI integrates customer needs and contracts these projects to FLSPs [3]. Before the logistics project is in operation, each member will reach a joint recognition plan for the revenue distribution problem. After the project is completed, the proceeds will be distributed according to the signed agreement. The key factor in the formation of the LSSC is that each member pursues the maximization of their own profits in the process of cooperation. Therefore, fair and reasonable revenue distribution is not only 
the guarantee for the successful operation of the LSSC, but also the member collaboration efficiency, creativity and the enthusiasm of production and operation activities [4]. Revenue distribution refers to the share of each member's share of total revenue or total profit. In general, there are three common modes of revenue distribution: output sharing mode, fixed payment mode and mixed mode [5]. In the actual operation process, the mixed mode is more common. The research in this paper is aimed at a mixed mode with general meaning. The first two modes can actually be regarded as special cases of mixed mode.

The exit research on revenue distribution is mostly based on the assumption of rational economic people, which is where the behavior is purely self-interested. However, in recent years, researchers have found that people have a fairness preference in addition to their selfinterested preferences, and they also pay attention to fairness preferences while pursuing personal interests [6,7]. Fairness preferences or inequality aversions impacts people's decision-making behavior. In an LSSC, there are multiple FLSPs, and they are no longer completely unrelated individuals, but have mutual influence. Therefore, considering the members' fair preference behavior in the revenue distribution model of the LSSC is very necessary [8]. Since multiple FLSPs cooperate with same LSI, these peers will compare their profits. When FLSP finds that its revenue is lower than the average level, he will generate disgust and choose negative completion, which is not conducive to supply chain efficiency [9-12]. Researchers define this behavior as peer-induced fairness concern, a common phenomenon in business [11,12]. In addition, the studies found that members pay attention to the comparison between their own earnings and the average revenue of the group in the game experiment. In the actual situation of the LSSC, not only does the revenue comparison between LSI and FLSP exist, but the peer comparison between FLSPs is more intense [13]. Peer-to-peer logistics companies vary in size and business focus, but the information on the average revenue of the industry can be learned. In the process of cooperation, FLSP compares its own revenue with the average industry revenue, and the comparison results affects FLSPs' decision.

This paper mainly answers the following questions: (1) What is the impact of FLSP's fairness preference behavior on the LSSC revenue distribution plan? (2) What is the impact of LSI's profit and supply chain utility on the total utility of FLSP? (3) What is the impact of the number of members with fairness preference on the revenue distribution plan and the decisions of each member, respectively?

In this paper, an improved revenue distribution decision model is established, which aims to maximize the utility of the entire supply chain based on maximizing the LSI's profit and the FLSPs' total utility, respectively. The BO model is an abbreviation of the model proposed by Bolton and Ockenfels [14] in 2000 to quantitatively describe the equity or fairness preference relationship between people or organizations. Then, the model is solved, and a series of numerical analysis are given. During the experiment, the defects of the existing BO model is shown, the BO model is improved and the influence of FLSP's behavior parameters on the revenue distribution is discussed.

This paper makes contributions in three aspects. Firstly, the fairness preference is introduced into the revenue distribution of LSSC, and the influence of fairness preference behavior on revenue distribution is discussed. Secondly, a two-player game is extended into a multi-player game and the comparison object is changed from the overall score to average level based on the $\mathrm{BO}$ model. The relative fairness revenue coefficient is added, which improves the existing BO model. Finally, some important conclusions are obtained.

The rest of the paper is organized as follows: Section 2 is a literature review of revenue distribution and fairness preferences. Section 3 is the problem description and assumptions. Section 4 considers the fairness preference of FLSP and establishes a revenue distribution model for the two-layer LSSC. Numerical analysis is carried out to analyze the impact of the fairness preference's degree on the results of revenue distribution. The improved BO model and numerical analysis are given in Section 5. The main conclusion and future research are given in Section 6. 


\section{Literature Review}

The literature review mainly involves fairness preference theory, fairness preference function and supply chain revenue distribution. The research objectives of this paper will be presented after summarizing the literature and its deficiency.

\subsection{Fairness Preference}

The traditional economic theory assumes that the subject of behavior is purely selfinterested, only pursues the maximization of personal interests and pays no attention to whether the behavioral motive or the distribution of revenue is fair. Samuelson (1993) [15] and Sen (1995) [16] first studied the behavioral characteristics of individuals. They pointed out that in reality individuals are not completely self-interested, but they are concerned about the interests of other related individuals. Additionally, many researchers have carried out further experiments, such as ultimatum, trust game, gift exchange, etc. The experimental results prove the conclusion that the individual is not completely rational and had limited self-interest [17-19]. This kind of behavior is manifested in that one individual will produce defamation behavior, when other individuals have higher interests; it will produce guilty behavior when other individuals have lower interests. Fairness preferences and self-interest preferences can affect people's decision-making behavior. However, in some cases, the effects are contradictory. For example, people may sacrifice some of their revenue to pursue fairness of revenue. Therefore, people's behavioral decisions are not only affected by profits, but also by social factors $[20,21]$.

In order to quantify the impact of fairness preferences on people's behavioral decisions, many economists have given theoretical models describing fairness preferences from different perspectives. Some scholars studied fairness preference from the perspective of reciprocity based on psychological game theory. Rabin (1993) [22] constructed an economic model that considers behavioral motivation and defined a kindness function. Dufwenberg and Kirchsteiger (2004) [23] extended Rabin's model to a multiplayer game and proposed a new solution concept-sequential reciprocal equilibrium. More scholars studied inequity aversion of actors from the perspective of revenue distribution. Representative models are the FS model proposed by Fehr and Schmidt [24] and the BO model proposed by Bolton and Ockenfels [14]. FS model is an is an abbreviation of the model proposed by Fehr and Schmidt in 1999, the model quantitatively defines fairness as self-centered inequity aversion. They think that people will compare their own revenue with others in order to judge whether the distribution of revenue is fair and propose a function of advantageous inequity and disadvantageous inequity. The BO model believes that players not only pay attention to their absolute revenues, but also pay attention to other individuals' welfare and the preference of fair distribution and motivation among members of society, paying attention to their share in the whole. The $\mathrm{BO}$ model emphasizes that participants compare their revenue with the average revenue of the group in the case of incomplete information, so the distribution of shares rather than the absolute difference is introduced into the utility function.

The application of fairness preference theory on the supply chain is also very rich. Loch et al. [25] demonstrated that social preferences that emerged in other contexts (e.g., experimental economics, anthropology, psychology) also affect the supply chain and are critical to performance. Pavlov et al. [26] found that the fairness preference and bounded rationality of supply chain subjects reduce the efficiency of supply chain, but information asymmetry will hinder the coordination of supply chain. Then, they used experimental methods to study and test the coordination and incentive efficiency of the supply chain after introducing fairness preference. The incomplete information about the degree of retailer's inequality aversion is the most convincing to the supplier's behavior [27]. On the basis of these, Qin et al. [28] further explained that people usually prefer simpler and theoretically superior contracts in practice, they conducted human-machine experiments and human-human experiments, and separated the impact of fair focusing on supply chain decisions from other effects such as bounded rationality. The experimental results show 
that disclosure of private cost information can stimulate cooperation between suppliers and retailers, However, not disclosing cost information to retailers will change pricing decisions and channel profit distribution will be more favorable to suppliers.

Later, many researchers have introduced fairness preference into the distribution problem of supply chain. Cui [29], one of the earliest researchers, studied the remuneration fairness between manufacturers and retailers in the supply chain. It was found that manufacturers can maximize channel profit and channel utility through a simple wholesale price higher than marginal cost. On the basis of Cui's research, Caliskandemirag et al. [30] took into account the non-linear market demand, and members' fairness concern regarding the wholesale price cooperation between manufacturers and retailers in the supply chain. It was found that the exponential demand function requires simpler conditions to achieve cooperation only when the retailer has fairness concerns. Recently, some researchers have extended Cui's model to include incomplete information [31]. Some researchers have extended it to the field of multiplayer games. For example, Ho et al. [32] constructed a supply chain model consisting of one supplier and two independent and homogeneous retailers, which extends fairness preference to the supply chain of multiplayer games. The experiment verifies the influence of distributive equity preference and peer focus equity preference on the channel member pricing strategy and proves that peer focus equity preference is stronger than distributive equity preference. Nie et al. [33] studied the quantity discount contract in the same structure supply chain. They found that some conclusions arising from wholesale price contracts cannot be applied to volume discount contracts. Liu et al. [34] introduced two fairness preferences into the order allocation problem of logistics service supply chain on the basis of the former two and found that the optimal utility of LSI increased with the second FLSP's peer-induced fairness preference and decreased with the distribution fairness preference of the first FLSP.

\subsection{Supply Chain Revenue Distribution}

There are many studies on supply chain revenue distribution. Most researchers studied the revenue sharing contract of a single manufacturer-retail supply chain [35-37]. Chauhan and Proth [38] proposed a supplier-retailer collaboration model based on profit sharing, which is based on the assumption that customer demand depends on retail price, maximizing overall profit and distributing profit proportional to its risk among partners. Zhang et al. [39] studied a one-manufacturer-two-retailers supply chain using a revenue-sharing contract in the case of demand disruption, which should adjust the original revenue-sharing contract according to the different conditions of demand interruption. There are many ways to allocate revenue in the supply chain. Pan et al. [40] discussed and compared the results of two cases that the manufacturer chooses the wholesale price contract and the revenue sharing contract with the retailer under the different channel power structures. Under certain conditions, it is more advantageous for the dominant party to use the revenue sharing contract. $\mathrm{Li}[41]$ found that the entire supply chain cannot be coordinated using fixed wholesale price contracts when retailers provide value-added services and have fair preference in a two-channel supply chain. Karakostas [42] conducted a simple commission-agent experiment in which the principal could choose between revenue sharing, bonuses and trust contracts. The results show that the revenue sharing contract is more effective and fairer.

For the specific logistics service supply chain, revenue distribution research is also a hot topic, especially with the development of logistics dynamic alliance, third-party logistics and shared logistics concepts, whether between alliance members, third-party logistics and participants in sharing logistics are also the research areas of the LSSC. Song and Zhang [43] aimed at the problem of revenue distribution between customers and third-party logistics providers, using closed-loop supply chain coordination management methods, designing profit-sharing contracts to coordinate the supply chain, so that both parties can do their utmost to maximize the overall profit and share profits together. Liu [44] studied the fairest revenue sharing coefficient when LSI and FLSPs applied fair entropy functions 
under stochastic demand conditions to realize revenue sharing contracts. Some researchers have studied the profit distribution problem in logistics joint distribution network based on cooperative game theory and improved Shapley value model [45]. Han [46] used the modified Shapely value to study the profit distribution problem of e-commerce logistics enterprise alliance under the condition of storage overload. Gan et al. [47] proposed an intensive distribution logistics network considering the sharing economy, analyzed the profit distribution mechanism of participants in the distribution network and proposed an improved interval Shapley value method considering satisfaction and contribution.

In recent years, many researchers have introduced fairness preferences into the LSSC. Wang et al. [48] introduced fairness preferences into the coordination of logistics service supply chain channels, and proposed that when LSI is disadvantageous inequity, channel coordination cannot be achieved. The study is about LSSC consisting of an LSI and an FLSP. Liu et al. [49] studied a two-stage supply chain consisting of an LSI and multiple FLSPs and established an order allocation model considering both the demand update and the fair preference caused by peer attention between FLSPs.

\subsection{Summary of Literature Review}

It can be seen from the above literature that the research on fairness preference behavior and its utility function, supply chain pricing considering member fairness preference and broader supply chain coordination, including supply chain revenue distribution, are relatively rich, as shown in Table 1. In the traditional supply chain, scholars mostly consider the impact of fairness on contracts design and fewer members. In the LSSC, Wang et al. [48] (2016) considered the distribution fairness preference of FLSP, and the comparison object is LSI, which studies the revenue distribution problem of the LSSC consisting of one LSI and one FLSP. However, the cooperation between an LSI and multiple FLSPs is studied, which is more complicated than the situation. Liu et al. [49] (2017) studied the order allocation problem in LSSC. The FLSP directly compares the order quantity. The research problem in this paper is a revenue distribution problem, and the FLSP is compared with the average revenue of the whole FLSPs. In the past, the FS model was used in much of the literature to describe the fairness preference utility function. The $\mathrm{BO}$ model is used in this paper, which is more suitable for the research background of this paper. The fairness preference of FLSP is considered and the $\mathrm{BO}$ model is applied to construct the utility function of the LSP. Then, the $\mathrm{BO}$ model was improved to establish a more suitable revenue distribution model. The influence of the FLSP's fairness preference and the number of FLSP members with inequity aversion on the revenue distribution is discussed, respectively.

Table 1. Differences between this article and related works.

\begin{tabular}{|c|c|c|c|c|c|c|}
\hline & Paper & $\begin{array}{l}\text { Research } \\
\text { Problem }\end{array}$ & $\begin{array}{l}\text { Supply Chain } \\
\text { Structure }\end{array}$ & $\begin{array}{c}\text { Fairness } \\
\text { Preference Type }\end{array}$ & $\begin{array}{c}\text { Fairness } \\
\text { Preference } \\
\text { Member }\end{array}$ & $\begin{array}{c}\text { Utility } \\
\text { Function } \\
\text { Model }\end{array}$ \\
\hline \multirow{3}{*}{$\begin{array}{l}\text { Traditional } \\
\text { supply chain }\end{array}$} & Cui et al. 2007 & $\begin{array}{l}\text { wholesale price } \\
\text { contracts }\end{array}$ & $\begin{array}{l}\text { one supplier and one } \\
\text { retailer }\end{array}$ & distributional & both & FS \\
\hline & $\begin{array}{l}\text { Ho et al. } \\
2014\end{array}$ & $\begin{array}{l}\text { wholesale price } \\
\text { contracts }\end{array}$ & $\begin{array}{l}\text { one supplier and two } \\
\text { retailers }\end{array}$ & $\begin{array}{l}\text { distributional and } \\
\text { peer-induced }\end{array}$ & retailers & FS \\
\hline & Nie et al. 2017 & $\begin{array}{l}\text { quantity discount } \\
\text { contracts }\end{array}$ & $\begin{array}{l}\text { one supplier and two } \\
\text { retailers }\end{array}$ & $\begin{array}{l}\text { distributional and } \\
\text { peer-induced }\end{array}$ & retailers & FS \\
\hline \multirow{4}{*}{ LSSC } & $\begin{array}{l}\text { Kouhpaenejad et al. } \\
2013\end{array}$ & $\begin{array}{l}\text { revenue } \\
\text { distribution }\end{array}$ & one LSI and one FLSP & none & none & none \\
\hline & Wang et al. 2016 & $\begin{array}{c}\text { revenue } \\
\text { distribution }\end{array}$ & one LSI and one FLSP & distributional & FLSP & FS \\
\hline & Liu et al. 2017 & order allocation & one LSI and n FLSPs & peer-induced & FLSPs & FS \\
\hline & This paper & $\begin{array}{l}\text { revenue } \\
\text { distribution }\end{array}$ & one LSI and n FLSPs & peer-induced & FLSPs & $\mathrm{BO}$ \\
\hline
\end{tabular}




\section{Problem Description and Assumptions}

This section shows the problem description and assumptions. In Section 3.1, the issue of revenue distribution and the decision-making process are described. In Section 3.2, the main assumptions in the model are listed.

\subsection{Problem Description}

The LSSC consists of a system consisting of one LSI and n FLSPs. LSI integrates its own and FLSPs logistics capabilities to meet the complex needs of customers. The logistics service capability provided to customers is partly from the LSI itself, and the rest comes from FLSPs. First, LSI signed a contract with the customer to integrate the customer's needs; LSI and FLSPs agreed to complete the project's revenue distribution ratio and sign the contract. Then, LSI assigns the project to the FLSP, and in the process, both parties input their own production factors-the effort level. Finally, the project is completed and each member shares revenue according to the contract. This article uses a hybrid payment model. The game time series for completing the entire project is shown in Figure 1.

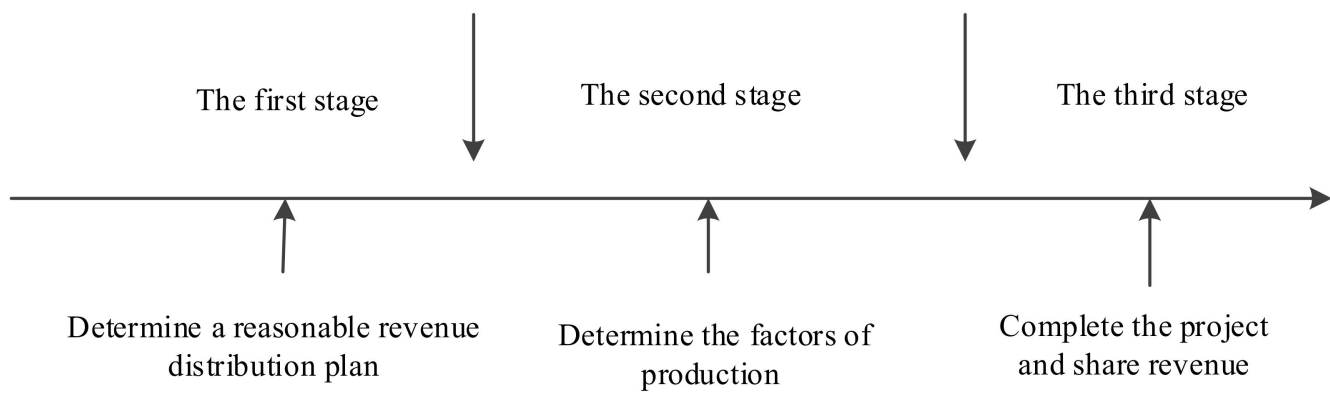

Figure 1. Game timeline.

\subsection{Assumption}

Hypothesis (H1): Customers, LSI and FLSPs are risk-neutral, and their monetary revenues are equivalent to utility.

Hypothesis (H2): In the process of implementing the project, LSI and FLSPs input the unobservable level of effort, which is private information, but can be verified by value added.

Hypothesis (H3): LSI is dominant in the process of revenue distribution, and LSI is also fair-neutral.

Hypothesis (H4): The ratio of revenue distribution is agreed between LSI and each FLSP, respectively, and different FLSPs are independent of each other.

\section{Modeling}

\subsection{Symbol Definition}

\begin{tabular}{cc}
\hline Symbol & Definition \\
\hline$P$ & The total contract price \\
$P_{1}$ & Fixed contract price \\
$\varphi$ & Optimization coefficient, $0 \leq \varphi \leq 1$ \\
$\varepsilon_{0}$ & LSI's efficiency coefficient, $0 \leq \varepsilon_{0} \leq 1$ \\
$\varepsilon_{i}$ & LSI's effort level, $0 \leq e_{0} \leq 1,1,2 \cdots, n$ \\
$e_{0}$ & FLSP's efficiency coeffient, $0 \leq \varepsilon_{i} \leq 1,2 \cdots, n$ \\
$e_{i}$ & FLSP I's effort level, $0 \leq e_{i} \leq 1, i=1,2 \cdots$ \\
$R_{i}$ & The fee that LSI paid to the FLSP $i$ \\
$P_{2 i}$ & Fixed contract price for LSI and FLSP $i$ \\
$\lambda_{i}$ & FLSP $i^{\prime}$ 's revenue distribution ratio, $0 \leq \lambda_{i} \leq 1$ \\
\hline
\end{tabular}




\begin{tabular}{cc}
\hline Symbol & Definition \\
\hline$C_{0}$ & Total fixed cost \\
$C_{00}$ & Fixed cost of LSI \\
$C_{0 i}$ & Fixed cost of FLSP $i$ \\
$C_{1}$ & Variable costs \\
$C_{10}$ & LSI's effort cost, $C_{10}=\frac{1}{2} \varphi P_{1} \rho_{0} e_{0}{ }^{2}$ \\
$C_{1 i}$ & FLSP $i^{\prime}$ s effort cost, $C_{1 i}=\frac{1}{2} \varphi P_{1} \rho_{i} e_{i}{ }^{2}$ \\
$\rho_{i}$ & Effort cost coefficient, $\rho_{i}>0, i=0, \cdots, n$ \\
$w_{i}$ & bottom-line revenue that FLSP $i$ can accept \\
\hline
\end{tabular}

\subsection{Modeling}

The establishment of the mathematical model for revenue distribution is divided into three steps. First, without considering the inequity aversion of FLSP, the total revenue of LSI, FLSP $i$, overall FLSP and supply chain is obtained. The fair-neutral revenue distribution model is the base of the improved revenue distribution model, and the experimental results of the fair-neutral revenue distribution model will be used to compare with the proposed improved revenue distribution model. Then, considering the inequity aversion of FLSP $i$, the BO model [14] is applied to describe the fairness preference of FLSP $i$. Finally, on the basis of the previous, an improved model of revenue distribution is established, which aims to maximize the utility of the supply chain. The detail of modeling is shown in the following parts.

(1) Fair-neutral revenue distribution model

LSI signs a contract with the customers

$$
P=P_{1}+\varphi P_{1}\left(\varepsilon_{0} e_{0}+\sum_{i=1}^{n} \varepsilon_{i} e_{i}\right)
$$

LSI signs a contract with each FLSP $i$

$$
R_{i}=P_{2 i}+\lambda_{i} \varphi P_{1}\left(\varepsilon_{0} e_{0}+\varepsilon_{i} e_{i}\right)
$$

Total cost

$$
C=C_{0}+C_{1}=\left(C_{00}+\sum_{i=1}^{n} C_{0 i}\right)+\left(C_{10}+\sum_{i=1}^{n} C_{1 i}\right)
$$

According to the above formulas, the revenue function of the supply chain, the LSI, FLSP $i$, and the overall FLSPs can be obtained.

The revenue of the supply chain

$$
\Pi=\pi_{1}+\sum_{\mathrm{i}=1}^{\mathrm{n}} \pi_{2 i}=P-C
$$

LSI's revenue

$$
\pi_{1}=P_{1}-\sum_{i=1}^{n} P_{2 i}+\sum_{i=1}^{n}\left(1-\lambda_{i}\right) \varphi P_{1}\left(\varepsilon_{0} e_{0}+\varepsilon_{i} e_{i}\right)-C_{00}-C_{10}
$$

FLSP $i$ 's revenue

$$
\pi_{2 i}=P_{2 i}+\lambda_{i} \varphi P_{1}\left(\varepsilon_{0} e_{0}+\varepsilon_{i} e_{i}\right)-C_{0 i}-C_{1 i}
$$

The FLSPs' total revenue

$$
\pi_{2}=\sum_{i=1}^{n} \pi_{2 i}
$$

(2) Inequity aversion revenue distribution model 
When LSI is fair-neutral, FLSP $i$ has inequity aversion, assume that the average revenue of the overall FLSPs is known for the FLSP $i$. Applying the BO model [14], and the utility of FLSP $i$ is

$$
v_{i}=a_{i} \pi_{2 i}-b_{i}\left(\pi_{2 i}-\frac{\pi_{2}}{n}\right)
$$

In Equation (8), $a_{i}$ and $b_{i}$ indicate the degree of FLSP $i$ 's attention to self-revenue and revenue distribution fairness, respectively, where $0<a_{i}, 0 \leq b_{i} \leq 1$.

$a_{i} / b_{i}$ indicates the degree of inequity aversion of FLSP $i$. Considering that most people pay more attention to their self-revenue than to revenue distribution fairness, this paper assumes $a_{i}>b_{i}, a_{i} / b_{i} \in(1,+\infty)$. The smaller $a_{i} / b_{i}$ is, the stronger the inequity aversion of FLSP $i$. The larger $a_{i} / b_{i}$ is, the more self-interesting FLSP $i$ is, and the weaker the inequity aversion is. When $a_{i}=1$ and $b_{i}=0$, it means that FLSP $i$ is fair-neutral.

The utility of the supply chain is

$$
U=\pi_{1}+V=\pi_{1}+\sum_{i=1}^{n} v_{i}
$$

(3) Revenue distribution model with constraints

$$
\max U
$$

s.t.

$$
\begin{gathered}
\lambda_{i} \in \operatorname{argmax}_{i} \\
1-\sum_{i=1}^{n} \lambda_{i} \in \operatorname{argmax} \pi_{1} \\
v_{i} \geq w_{i}, i=1,2 \cdots, n \\
0 \leq e_{i} \leq 1, i=0,1, \cdots, n \\
0 \leq \lambda_{i} \leq 1, i=1,2, \cdots, n \\
0 \leq \varepsilon_{i} \leq 1, i=0,1, \cdots, n
\end{gathered}
$$

Equation (10) indicates that the goal is to maximize the utility of supply chain; Equations (11) and (12) indicate that the revenue distribution scheme can maximize the revenue of each member. Equation (13) indicates that the utility of FLSP $i$ cannot be lower than its bottom-line revenue; Equations (14)-(16) represent the value range of the effort level, the revenue distribution coefficient and the efficiency coefficient, respectively.

\subsection{Numerical Analysis}

This section verifies the validity of the proposed model by numerical analysis, and analyzes the impact of fairness preferences on LSI, FLSP and supply chain utility. The numerical analysis is programed and simulated using Matlab R2017a software.

\subsubsection{Initial Data}

An LSI collaborates with three FLSPs to complete a logistics project. For the convenience of calculation, it is assumed that the efficiency coefficient of all enterprises is 1 , $\varepsilon_{i}=1, i=1,2 \cdots, n$; fixed contract price $P_{1}=400, P_{2 i}=(90,91,92), i=1,2,3$, optimization coefficient $\varphi=0.5$, fixed $\operatorname{cost} C_{0 i}=(40,50,51,52), i=0,1,2,3$, effort cost coefficient $\rho_{i}=(0.3,0.4,0.41,0.42), i=0,1,2,3$ and bottom line revenue $w_{i}=(50,60,70), i=1,2,3$. The parameter settings in this paper refer to the previous literature [50] and have been modified appropriately.

\subsubsection{The Influence of Fairness Preference on Revenue Distribution}

The experiments are conducted to study the impact of the degree of FLSPs' inequity aversion and the number of FLSPs with inequity aversion on the distribution scheme. The 
experiment is divided into two categories: (1) members are fair-neutral among FLSPs; (2) members are extremely inequity aversion among FLSPs. In order to study the impact of the number of FLSPs with inequity aversion on the distribution scheme, four cases are considered in the two types of experiments, namely, fair-neutral FLSPs accounted for the majority and minority, and FLSPs with extreme inequity aversion were majority and minority. By setting the inequity aversion parameters of FLSP $i$, the effects caused by the different degrees of FLSP $i$ 's inequity aversion on the distribution scheme are studied. Since the basic conditions of the three FLSPs are similar, in order to facilitate understanding, this paper chooses to change the inequity aversion parameters of FLSP1 and FLSP2, which does not affect the final conclusion.

As can be seen from Section 4.2, The parameters value $\left(a_{i}=1, b_{i}=0\right)$ indicates that FLSP $i$ is fair-neutral. In order to compare with this, this paper sets $a_{i}=1(i=1,2,3)$ in the three FLSPs inequity aversion parameters and changes $b_{i}$ which means the different degrees of FLSP $i^{\prime}$ inequity aversion. The larger $b_{i}$, the stronger the inequity aversion of FLSP $i . b_{i}=1$ indicates that FLSP $i$ is extremely inequity aversion.

(1) Fair-neutral FLSPs among members

Situation 1. Fair-neutral FLSPs account for the majority.

For situation 1 , the inequity aversion parameters of the three FLSPs are $a_{i}=1$ $(i=1,2,3)$ and $b_{i}=0(i=2,3)$, where FLSP2 and FLSP3 are fair-neutral. The experiments are carried out by changing the value of inequity aversion parameters of FLSP1, $b_{1}$ increasing from 0 to 1 , which corresponds to different degrees of FLSP1' inequity aversion, from fair-neutral to extremely inequity aversion. The results of experiments are shown in Table 2, Figures 2 and 3.

Table 2. Experimental results for Situation 1.

\begin{tabular}{cccccc}
\hline $\boldsymbol{b}_{1}$ & $\boldsymbol{\lambda}_{\boldsymbol{i}}(\boldsymbol{i}=1,2,3)$ & $\boldsymbol{U}$ & $\boldsymbol{\pi}_{1}$ & $\boldsymbol{V}$ & $\boldsymbol{v}_{\boldsymbol{i}}(\boldsymbol{i}=1,2,3)$ \\
\hline 0 & $0.201,0.1961,0.1914$ & 782.88 & 549.91 & 232.98 & $78.78,77.64,76.56$ \\
0.1 & $0.0422,0.2838,0.2758$ & 784.60 & 539.94 & 244.67 & $50.37,98.18,96.11$ \\
0.2 & $0,0.3659,0.3505$ & 788.95 & 509.21 & 279.75 & $49.98,116.99,112.77$ \\
0.3 & $0,0.4494,0.4266$ & 794.53 & 471.13 & 323.40 & $58.49,135.75,129.16$ \\
0.4 & $0,0.5389,0.5029$ & 801.31 & 429.55 & 371.76 & $69.62,156.53,145.61$ \\
0.5 & $0,0.6226,0.5875$ & 809.36 & 385.37 & 423.99 & $83.43,175.93,164.64$ \\
0.6 & $0,0.7379,0.6501$ & 818.76 & 335.75 & 483.02 & $100.5,205.87,176.64$ \\
0.7 & $0,0.8983,0.6890$ & 829.64 & 274.52 & 555.12 & $122.32,252.91,179.9$ \\
0.8 & $0,0.999,0.7363$ & 842.15 & 227.33 & 614.82 & $144.17,282.91,187.74$ \\
0.9 & $0,0.9978,0.9235$ & 855.85 & 175.26 & 680.58 & $169.37,270.06,241.16$ \\
1 & $0.0001,0.9998,0.9995$ & 870.76 & 150.57 & 720.20 & $190.05,265.63,264.52$ \\
\hline
\end{tabular}

It can be seen from Table 2, Figures 2 and 3, that the distribution ratios of the three FLSPs are very similar, while they are fair-neutral. Additionally, $\lambda_{1}$ is the highest. As Figure 2 illustrates, $\pi_{1}$ is much higher than $v_{i}$, and the supply chain has the lowest utility. Combined with Figure 3 , the stronger the inequity aversion of FLSP1 is, the lower $\lambda_{1}$ is, and $v_{1}$ is reduced first and then increased. Meanwhile, the ratio and utility of fair-neutral FLSPs increases and $U$ increases.

The reason is as follows: It can be seen from the BO model that, when the profit of FLSP1 is lower than the overall average profit of FLSPs, that is, $\pi_{21}<\frac{\pi_{2}}{n},-b_{1}\left(\pi_{21}-\frac{\pi_{2}}{n}\right)$ is positive and FLSP1 shows an altruistic tendency. Therefore, when FLSP1 is inequity averse, its distribution ratio decreases, and the ratio of fair-neutral FLSPs increases. Thus, the greater the difference between FLSP1 and the average profit, the more favorable it is for FLSP1. The effort level and $v_{1}$ decreases with decreasing of $\lambda_{1}$. The effort level of fair-neutral FLSPs increase with the distribution ratio, and the added value is much larger. Therefore, fair-neutral FLSPs' utility increase, $\pi_{1}$ decreases and $U$ increases. 


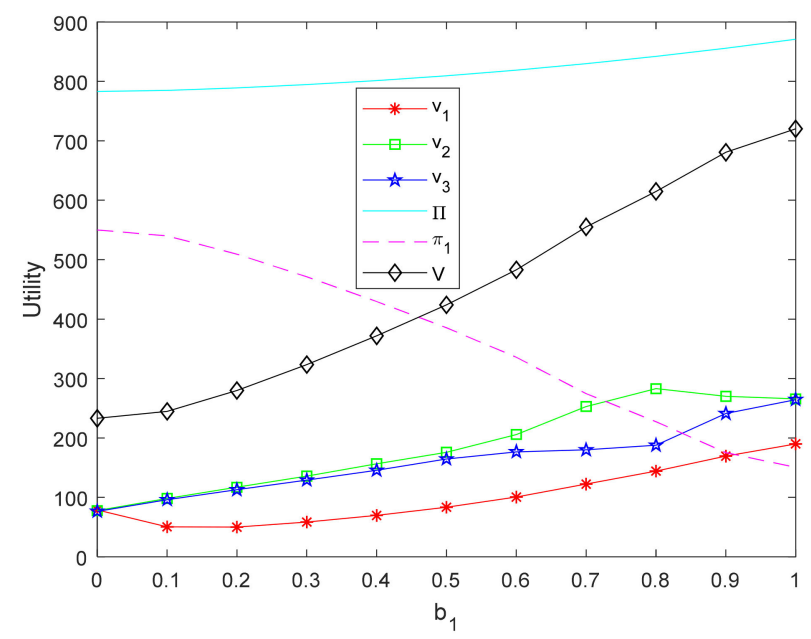

Figure 2. The effect of inequity aversion parameters on the utilities for Situation 1.

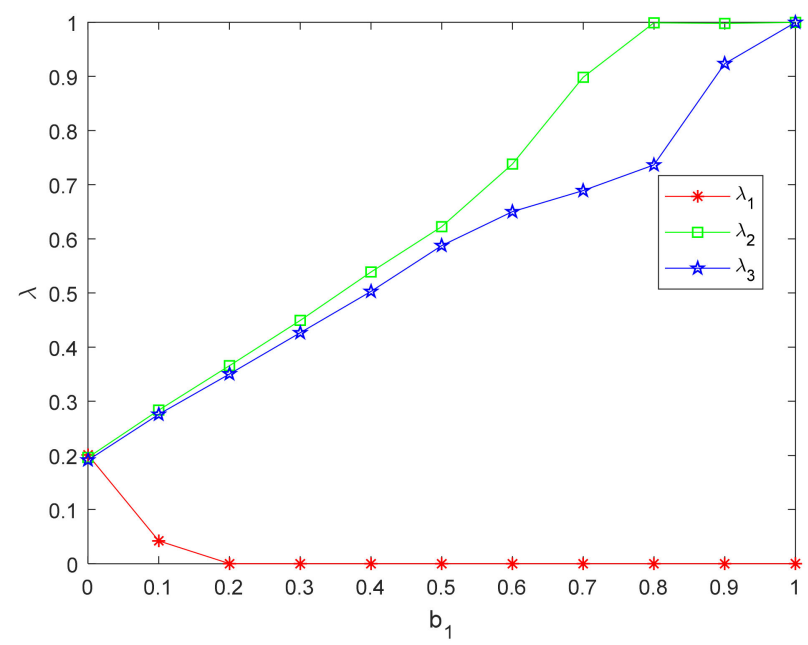

Figure 3. The effect of inequity aversion parameters on the distribution ratios for Situation 1.

The added value added by the fair-neutral FLSPs increase, when the inequity aversion of FLSP1 is relatively strong. For FLSP1 with inequity aversion, the positive utility caused by the difference becomes the main part of its utility and slowly increases. The actual profit of FLSP1 decreases with the increase of its inequity aversion, and FLSP1 will be in a more disadvantageous position, which is inconsistent with the actual situation.

Situation 2. Fair-neutral FLSPS account for the minority.

For situation 2, the inequity aversion parameters of the three FLSPs are $a_{i}=1$ $(i=1,2,3)$ and $b_{3}=0$, where only FLSP3 is fair-neutral. The experiments are carried out by changing the value of inequity aversion parameters of FLSP1 and FLSP2, $b_{1}$ and $b_{2}$, from 0 to 1 , respectively. The experimental results are shown in Table 3 and Figures 4 and 5, respectively.

It can be seen from Table 3, Figures 4 and $5, \lambda_{1}$ and $\lambda_{2}$ are very low, and the fair-neutral FLSP distribution ratio $\lambda_{3}$ is very high, while FLSP1 and FLSP2 are relatively inequity averse, $a_{1}=a_{2}=1$. The rest of the trend is similar to Situation 1 and will not be repeated here. The reasons are the same as in Situation 1, FLSP1 and FLSP2 with inequity aversion have a greater difference from the average level, respectively. The positive utility and $U$ are both greater than utilities in Situation 1. 
Table 3. Experimental results for Situation 2.

\begin{tabular}{cccccc}
\hline $\boldsymbol{b}_{1}, \boldsymbol{b}_{2}$ & $\boldsymbol{\lambda}_{\boldsymbol{i}}(\boldsymbol{i}=1,2,3)$ & $\boldsymbol{U}$ & $\boldsymbol{\pi}_{1}$ & $\boldsymbol{V}$ & $\boldsymbol{v}_{\boldsymbol{i}}(\boldsymbol{i}=1,2,3)$ \\
\hline 0 & $0.201,0.1961,0.1914$ & 782.88 & 549.91 & 232.98 & $78.78,77.64,76.56$ \\
0.1 & $0.1027,0.1006,0.4017$ & 785.05 & 534.88 & 250.17 & $60.46,60.08,129.63$ \\
0.2 & $0.0001,0.0002,0.7070$ & 793.42 & 461.40 & 332.02 & $52.48,52.5,227.04$ \\
0.3 & $0.0012,0.0001,0.9994$ & 809.91 & 340.54 & 469.38 & $69.23,69.13,331.02$ \\
0.4 & $0.0001,0.0008,0.9993$ & 829.31 & 340.60 & 488.71 & $78.82,78.88,331.01$ \\
0.5 & $0.0006,0.0019,0.9995$ & 848.67 & 340.43 & 508.25 & $88.59,88.68,330.98$ \\
0.6 & $0.0002,0.0003,0.9999$ & 868.17 & 340.35 & 527.82 & $98.28,98.28,331.26$ \\
0.7 & $0.0008,0,0.9997$ & 887.55 & 340.43 & 547.12 & $108,107.96,331.17$ \\
0.8 & $0.0003,0.0003,0.9994$ & 906.93 & 340.57 & 566.36 & $117.65,117.65,331.06$ \\
0.9 & $0.0011,0.0008,1$ & 926.34 & 340.23 & 586.11 & $127.45,127.45,331.21$ \\
1 & $0.0003,0.0003,0.9992$ & 945.69 & 340.66 & 605.03 & $137.02,137.02,330.99$ \\
\hline
\end{tabular}

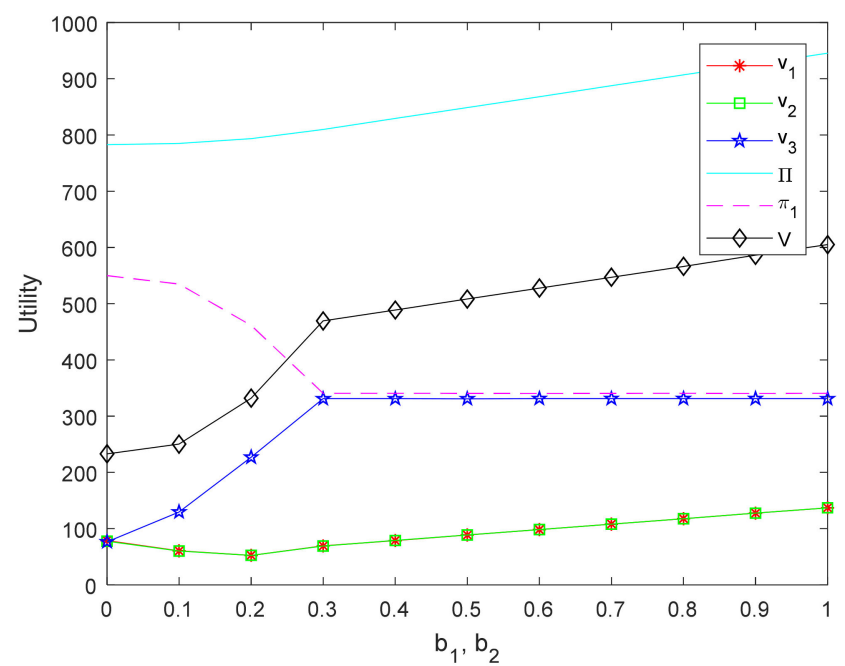

Figure 4. The effect of inequity aversion parameters on the utilities for Situation 2.

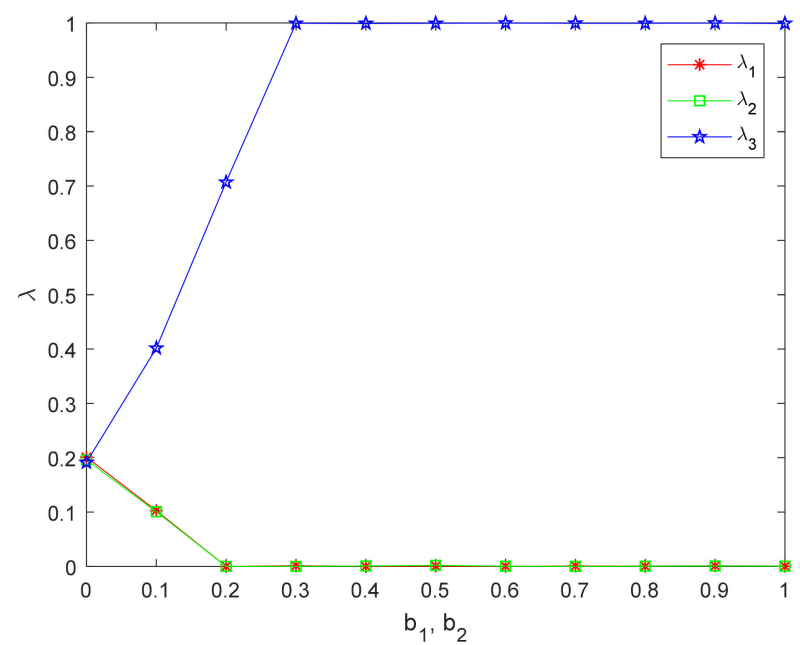

Figure 5. The effect of inequity aversion parameters on the distribution ratios for Situation 2.

(2) Extremely inequity aversion FLSPs among members

Situation 3. Extremely inequity aversion FLSPs account for the majority.

For situation 3, the inequity aversion parameters of the three FLSPs are $a_{i}=1$ $(i=1,2,3)$ and $b_{i}=1(i=2,3)$ where FLSP2 and FLSP3 are extremely inequity 
aversion. The experiments are carried out by changing the value of inequity aversion parameters of FLSP1, $b_{1}$, increasing from 0 to 1 . The experimental results are shown in Table 4 and Figures 6 and 7.

Table 4. Experimental results for Situation 3.

\begin{tabular}{cccccc}
\hline $\boldsymbol{b}_{1}$ & $\boldsymbol{\lambda}_{\boldsymbol{i}}(\boldsymbol{i}=1,2,3)$ & $\boldsymbol{U}$ & $\boldsymbol{\pi}_{1}$ & $\boldsymbol{V}$ & $\boldsymbol{v}_{\boldsymbol{i}}(\boldsymbol{i}=1,2,3)$ \\
\hline 0 & $0.9996,0.0009,0.0016$ & 948.96 & 340.38 & 608.58 & $333.01,137.78,137.78$ \\
0.1 & $1,0.0001,0.0001$ & 929.64 & 340.32 & 589.33 & $313.77,137.78,137.78$ \\
0.2 & $0.9996,0.0007,0.0003$ & 910.00 & 340.46 & 569.54 & $294.04,137.75,137.75$ \\
0.3 & $1,0.0013,0.0012$ & 890.42 & 340.20 & 550.23 & $274.57,137.83,137.83$ \\
0.4 & $1,0.0002,0.0006$ & 870.96 & 340.29 & 530.68 & $255.09,137.8,137.8$ \\
0.5 & $0.9993,0.0002,0.0003$ & 851.39 & 340.62 & 510.76 & $235.36,137.7,137.7$ \\
0.6 & $0.9997,0.0011,0.0003$ & 831.85 & 340.39 & 491.45 & $215.91,137.77,137.77$ \\
0.7 & $0.9992,0.0001,0.0002$ & 812.32 & 340.68 & 471.64 & $196.28,137.68,137.68$ \\
0.8 & $0.7536,0.0001,0.0002$ & 794.63 & 443.71 & 350.91 & $135.08,107.92,107.92$ \\
0.9 & $0.4258,0.0984,0.0964$ & 785.40 & 529.63 & 255.77 & $88.79,83.49,83.49$ \\
1 & $0.201,0.1961,0.1914$ & 782.88 & 549.91 & 232.98 & $77.66,77.66,77.66$ \\
\hline
\end{tabular}

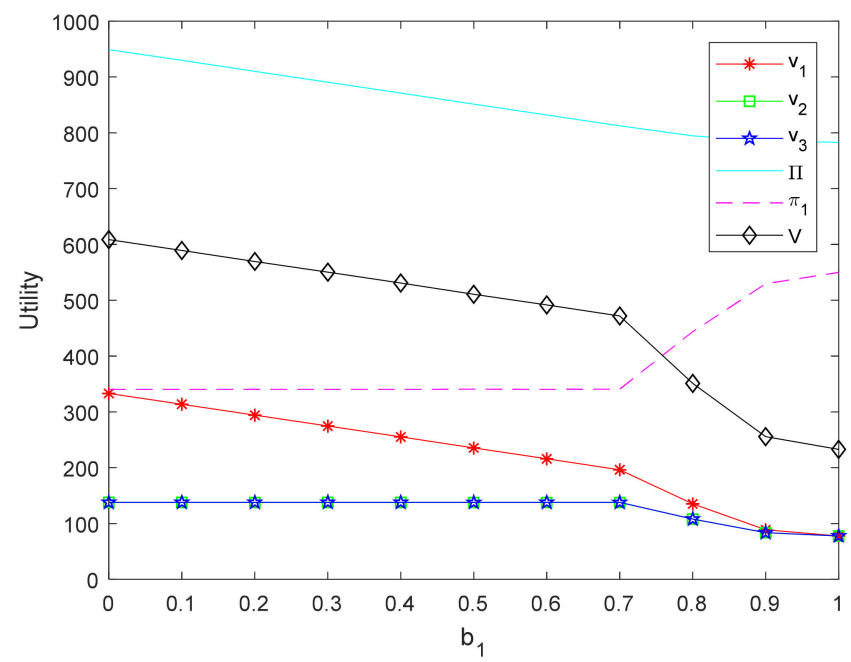

Figure 6. The effect of inequity aversion parameters on the utilities for Situation 3.

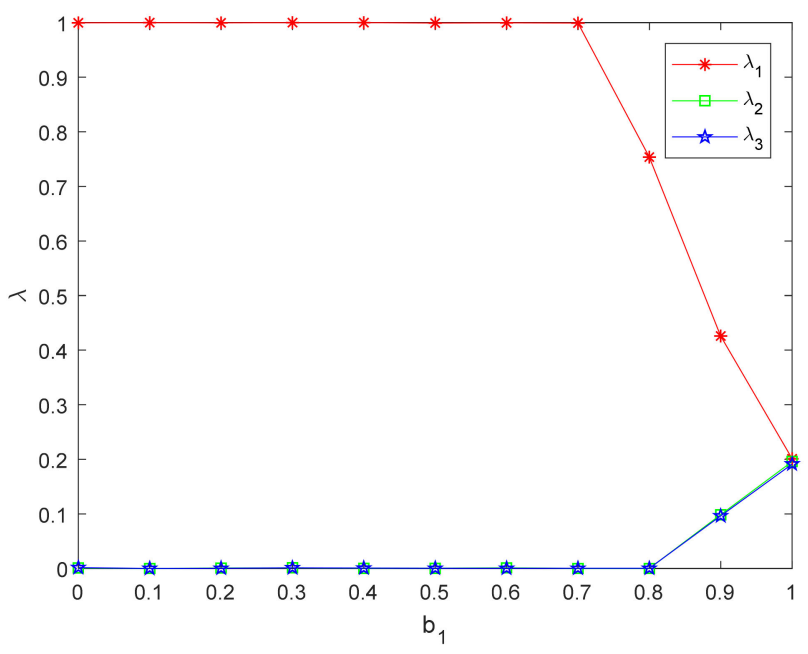

Figure 7. The effect of inequity aversion parameters on the distribution ratios for Situation 3.

It can be seen from Table 4 and Figures 6 and 7 that the fair-neutral FLSP1's distribution ratio $\lambda_{1}$ is very high, the distribution ratios of FLSPs with extremely inequity aversion $\lambda_{2}$ 
and $\lambda_{3}$, are very low, when FLSPs with extremely inequity aversion are in majority from Figure 6. The stronger the inequity aversion of FLSP1 is, the lower $\lambda_{1}$ and the lower $v_{1}$ is. As Figure 7 illustrates, the ratio of members who are extremely inequity aversion will increase, their utilities and $U$ will decrease, while $\pi_{1}$ will increase.

The reason is as follows: When the profit of FLSP1 is higher than the average profit of the whole FLSPs, that is $\pi_{21}>\frac{\pi_{2}}{n}$, advantageous inequity negative utility is generated by $-b_{1}\left(\pi_{21}-\frac{\pi_{2}}{n}\right)$ for FLSP1 with inequity aversion. However, the profit of FLSP, which has extremely inequity aversion, is far lower than the average profit, showing an "altruistic" tendency and producing positive utility. The ratios of FLSPs with extremely inequity aversion is very low, and the disadvantageous inequity positive utility is very large. The fair-neutral FLSP has the highest distribution ratio, the highest effort level, the largest value added and no inequity negative utility. The supply chain has the most utility. FLSP1's $\lambda_{1}$ and efforts level decreases, as it becomes more and more inequity averse. Additionally, there is still advantageous inequity negative utility, so its utility will be reduced. The ratios of FLSPs that are extremely inequity averse will increase, the positive utility brought by the difference with the average profit will become smaller and smaller, so their utilities will also decrease. Although LSI's revenue is increasing, it is not enough to offset the decline in FLSPs, so the utility of supply chain is reduced.

Situation 4. Extremely inequity aversion FLSPs account for the minority.

For situation 4 , the inequity aversion parameters of the three FLSPs are $a_{i}=1$ $(i=1,2,3)$ and $b_{3}=1$, respectively, where FLSP3 is extremely inequity averse. The experiments are carried out by changing the value of inequity aversion parameters of FLSP1 and FLSP2, $b_{1}$ and $b_{2}$, from 0 to 1 , respectively. The experimental results are shown in Table 5 and Figures 8 and 9.

Table 5. Experimental results for Situation 4.

\begin{tabular}{cccccc}
\hline $\boldsymbol{b}_{1}, \boldsymbol{b}_{2}$ & $\boldsymbol{\lambda}_{\boldsymbol{i}}(\boldsymbol{i}=1,2,3)$ & $\boldsymbol{U}$ & $\boldsymbol{\pi}_{1}$ & $\boldsymbol{V}$ & $\boldsymbol{v}_{\boldsymbol{i}}(\boldsymbol{i}=1,2,3)$ \\
\hline 0 & $1,0.9976,0.0001$ & 873.42 & 151.12 & 722.29 & $266.82,264.9,190.57$ \\
0.1 & $0.9995,0.9846,0.0001$ & 858.36 & 155.50 & 702.85 & $259.72,253.68,189.45$ \\
0.2 & $0.9981,0.7979,0$ & 844.16 & 211.44 & 632.72 & $258.59,199.2,174.93$ \\
0.3 & $0.9505,0.6736,0$ & 831.27 & 260.28 & 570.99 & $238.78,170.32,161.89$ \\
0.4 & $0.7695,0.6671,0$ & 819.97 & 321.69 & 498.28 & $187,166.2,145.08$ \\
0.5 & $0.6535,0.5923,0$ & 810.24 & 375.47 & 434.77 & $157.34,147.49,129.93$ \\
0.6 & $0.5481,0.5193,0$ & 801.94 & 423.01 & 378.93 & $133.17,129.61,116.16$ \\
0.7 & $0.4622,0.4388,0$ & 794.96 & 465.00 & 329.96 & $114.19,112.14,103.63$ \\
0.8 & $0.3736,0.3574,0$ & 789.23 & 505.80 & 283.43 & $96.63,95.73,91.07$ \\
0.9 & $0.2903,0.2819,0.0401$ & 784.76 & 537.46 & 247.30 & $83.12,82.9,81.28$ \\
1 & $0.201,0.1961,0.1914$ & 782.88 & 549.91 & 232.98 & $77.66,77.66,77.66$ \\
\hline
\end{tabular}

It can be seen from Table 5 and Figures 8 and 9 that when only FLSP3 is extremely inequity averse, $\lambda_{3}$ is very low, and the fair-neutral FLSPs distribution ratios, $\lambda_{1}$ and $\lambda_{2}$, are very high. The stronger the inequity aversion of FLSP1 and FLSP2 are, the smaller the distribution ratios are and the lower the utility are. For the FLSP3 with extreme inequity aversion, $\lambda_{3}$ is slowly increasing and $v_{3}$ is decreasing. $\pi_{1}$ has increased, while $V$ and $U$ have decreased.

The reason is the same as situation 3, and the difference between FLSP3 with extremely inequity aversion and the average level is small, the positive effect is smaller, the number of FLSPs with weak degree of inequity aversion is large, and the negative utility compared with the average level is larger, so $U$ is lower overall than situation 3. 


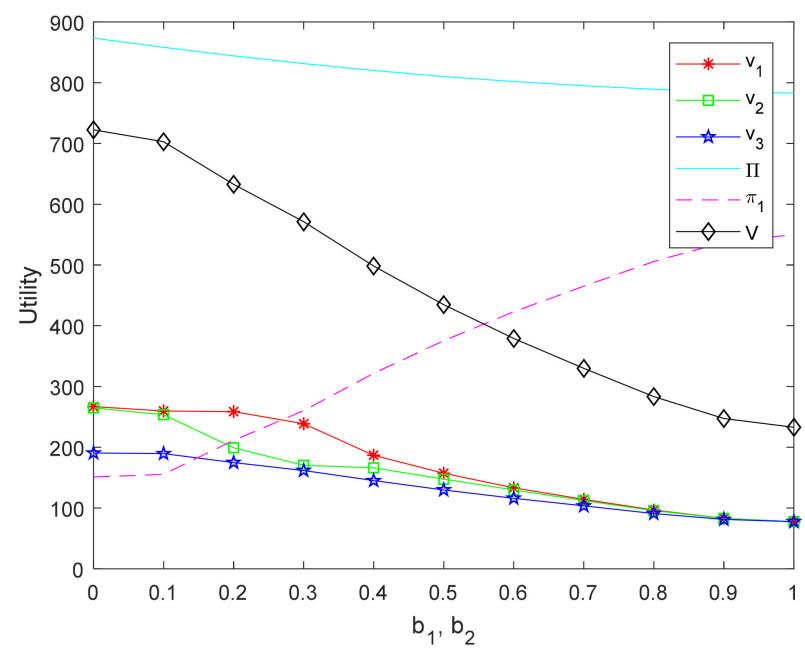

Figure 8. The effect of inequity aversion parameters on the utilities for Situation 4.

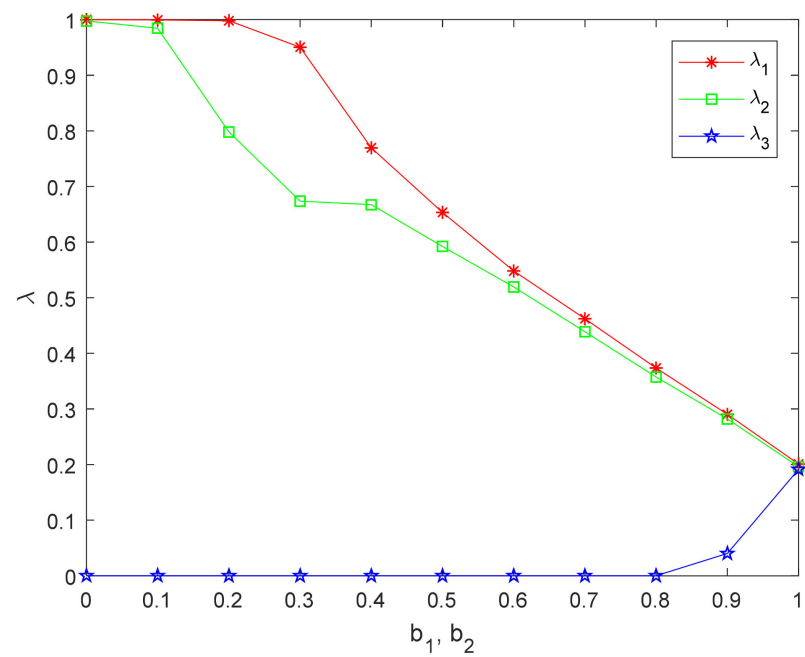

Figure 9. The effect of inequity aversion parameters on the distribution ratios for Situation 4 .

(3) Summary of the experiments

Compare the supply chain utility of the four cases, as shown in Figure 10. It can be seen that the supply chain has the lowest utility while all FLSPs are extremely inequity aversion or fair-neutral; the supply chain has the highest utility, while there is only one fair-neutral FLSP and the other two FLSPs are extremely inequity aversion. However, in practice, people are not satisfied because they are below average. On the contrary, most people hate that they are below average in fact. The experimental results from the original $\mathrm{BO}$ model are not consistent with the actual situation. 


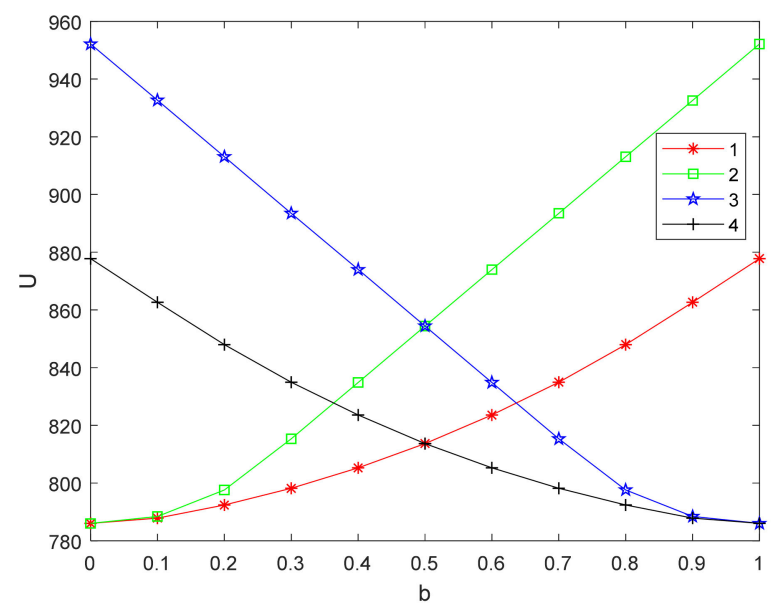

Figure 10. Comparison of the utility of supply chain in four situations.

\section{Improved BO Model}

\subsection{Model}

Due to the previous experiments results, it can be clearly seen that the model in Section 4.2 has obvious defects when the profit of FLSP members are below the average. It is a disadvantage for the FLSP who use the utility function based on the basic BO model. The profit of the FLSP will decrease while its degree of inequity aversion increase, which is very unrealistic.

In other words, the model proposed in Section 4.2 successfully portrays the inequity aversion of members when they are in advantage positions but cannot express the situation of disadvantageous inequity aversion of members. The comparison with the average should also be negative when members are at a disadvantage. The ERC model proposed in the paper by Bolton and Ockenfels (2000) [14], in the case of a two-person game, the utility function is

$$
v_{i}\left(c \sigma_{i}, \sigma_{i}\right)=a_{i} c \sigma_{i}-\frac{b_{i}}{2}\left(\sigma_{i}-\frac{1}{2}\right)^{2}, a_{i}>0, b_{i} \geq 0
$$

where, $\sigma_{i}=\sigma_{i}\left(c, y_{i}\right)=\left\{\begin{array}{l}y_{i} / c, c>0 \\ 1 / n, c=0\end{array}\right.$ is the relative share of i's revenue and $c=\sum_{i=1}^{n} y_{i}$ is the total monetary revenue. Fehr et al. [51] suggested that behavior-related comparisons are more local, i.e., compared with colleagues or compared with their mean. Therefore, the model is modified as follows according to the previous literature.

The utility of FLSP $i$ obtained by applying the improved BO model is

$$
v_{i}=a_{i} \pi_{2 i}-b_{i}\left(\pi_{2 i}-\phi_{i} \frac{\pi_{2}}{n}\right)^{2}
$$

where, $\phi_{i}$ is the coefficient of FLSP $i$ 's revenue relative to the average of overall FLSPs. The definition here mainly refers to the literature of Cui [18]. $\phi_{i}$ is named as the relative fairness revenue coefficient, which is a positive exogenous parameter, and the model can be extended to any case of $\phi_{i}$. The meaning of the rest of the parameters in the formula are exactly the same as the previous one.

In the second item, FLSP $i$ compares its self-revenue with the average revenue of the overall FLSPs, which is more reasonable than comparing the relative share of the selfrevenue with the average in the original $\mathrm{BO}$ model. Compared with the $\mathrm{BO}$ model used in previous research, improved $\mathrm{BO}$ model, Equation (18), adopts the difference squared, which not only to express the advantageous inequity aversion of FLSP, but also to show the disadvantageous inequity aversion, and avoids the disadvantage that the utility is increased when the FLSP is at a disadvantage in the foregoing.

Substituting Equation (18) for Equation (8), the rest of the mathematical model of revenue distribution is the same as in Section 4.2 and will not be repeated here. 


\subsection{Numerical Analysis}

\subsubsection{The Influence of Fairness Preference on Revenue Distribution}

The initial data of the case is the same as in Section 4.3.1. Since there's little difference on the basic data of the three FLSPs, it can be considered that each FLSP has the same status in the overall peer. Therefore, $\phi_{i}(i=1,2,3)$, takes the same value, 1 , for each FLSP $i$.

(1) Fair-neutral FLSP among members

Situation 1. Fair-neutral FLSPs account for the majority.

For situation 1 , the inequity aversion parameters of the three FLSPs are $a_{i}=1$ $(i=1,2,3)$ and $b_{i}=0(i=2,3)$ where FLSP2 and FLSP3 are fair-neutral. The experiments are carried out by changing the value of inequity aversion parameters of FLSP1, $b_{1}$ increases from 0 to 0.3 , which corresponds to different degrees of FLSP1' inequity aversion, from fair-neutral to inequity aversion. The results of experiments are shown in Table 6, Figures 11 and 12.

It can be seen from Table 6 that FLSP1 has the greatest distribution ratio and greatest utility than other FLSPs, when all three FLSPs are fair-neutral. From Figures 11 and $12, \lambda_{1}$ and $v_{1}$ will decrease, but the ratio of fair-neutral members, $\lambda_{2}$ and $\lambda_{3}$ will increase when FLSP1 is inequity aversion. The distribution ratio is no longer affected by $b_{1}$ when $v_{1}$ is the same as the average.

Table 6. Experimental results for Situation 1.

\begin{tabular}{cccccc}
\hline $\boldsymbol{b}_{1}$ & $\boldsymbol{\lambda}_{\boldsymbol{i}}(\boldsymbol{i}=1,2,3)$ & $\boldsymbol{U}$ & $\boldsymbol{\pi}_{1}$ & $\boldsymbol{V}$ & $\boldsymbol{v}_{\boldsymbol{i}}(\boldsymbol{i}=1,2,3)$ \\
\hline 0 & $0.201,0.1961,0.1914$ & 782.88 & 549.91 & 232.98 & $78.78,77.64,76.56$ \\
0.02 & $0.1962,0.1984,0.1937$ & 782.88 & 549.95 & 232.93 & $77.7,78.16,77.07$ \\
0.04 & $0.1961,0.1985,0.1937$ & 782.88 & 549.95 & 232.93 & $77.68,78.18,77.07$ \\
0.06 & $0.196,0.1985,0.1938$ & 782.88 & 549.95 & 232.93 & $77.66,78.18,77.09$ \\
0.08 & $0.196,0.1985,0.1938$ & 782.88 & 549.95 & 232.93 & $77.66,78.18,77.09$ \\
0.1 & $0.196,0.1985,0.1938$ & 782.88 & 549.95 & 232.93 & $77.66,78.18,77.09$ \\
0.2 & $0.196,0.1985,0.1938$ & 782.88 & 549.95 & 232.93 & $77.66,78.18,77.09$ \\
0.3 & $0.1959,0.1985,0.1938$ & 782.88 & 549.97 & 232.91 & $77.64,78.18,77.09$ \\
\hline
\end{tabular}

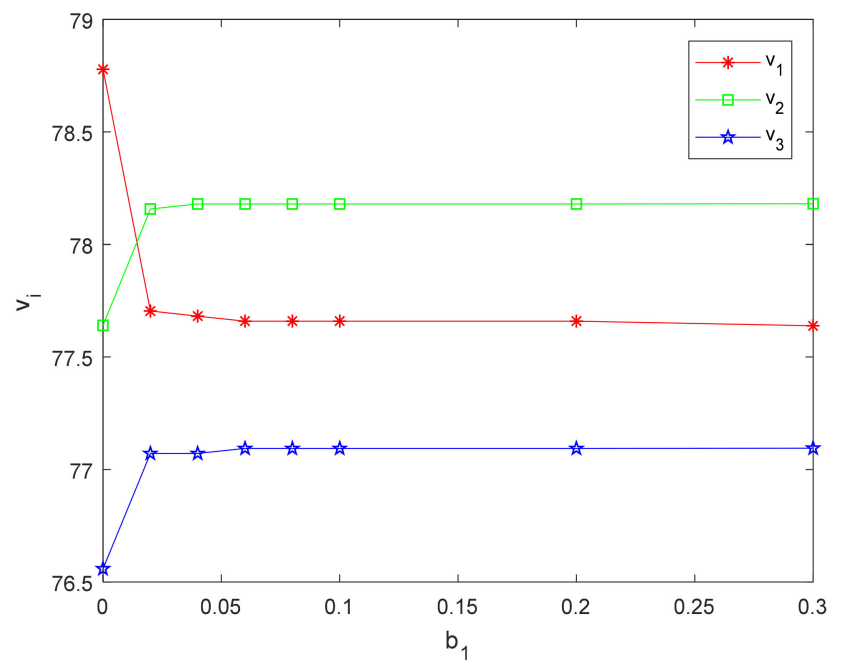

Figure 11. The effect of inequity aversion parameters on $v_{i}(i=1,2,3)$ for Situation 1. 


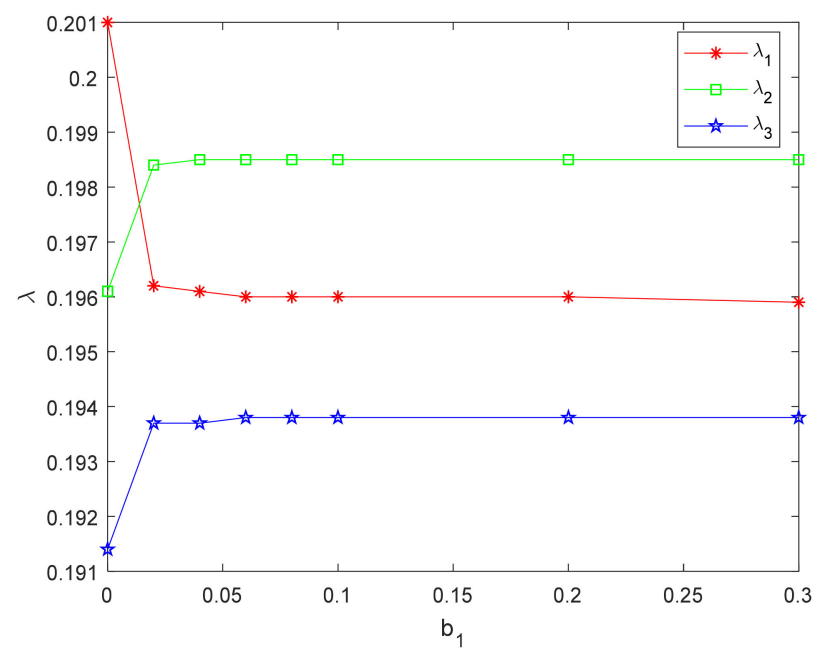

Figure 12. The effect of inequity aversion parameters on the distribution ratios for Situation 1.

The reasons are as follows: FLSP1 is above average and in an advantageous position while members are fair-neutral. Therefore, negative effects will be generated by advantageous inequity aversion when FLSP1 has inequity aversion. In order to reduce the gap with the average revenue, FLSP1 gives up part of the revenue to other members and reduces the distribution ratio, so that the revenue of the three FLSPs is substantially the same. The negative utility produced by comparison with the average is 0 , and the supply chain has the greatest utility.

Compared with situation 1 in Section 4.3.2, the distribution ratio solved by the original model is too low for members with inequity aversion who seek for greater adverse inequity positive utility, and the fair-neutral member distribution ratio is too high. This is not realistic. With the improved BO model, FLSP1 with inequity aversion only gives up part of its own interests, and the distribution ratio is slightly reduced to make the revenue distribution fairer.

In order to maximize the utility of the supply chain and reduce the inequity aversion negative utility, the $\lambda_{i}$ of the three FLSPs must be similar, etc., the other three situations should be the same.

What are the impacts on the revenue distribution plan when the three FLSPs value different degrees of their own revenue? The following experiment is carried out for this issue.

B. The inequity aversion parameters of the three FLSPs are $a_{1}=1.2, a_{2}=1, a_{3}=1$, $b_{i}=0, i=2,3$, where FLSP2 and FLSP3 are fair-neutral. The parameters of the three FLSPs for their own revenue, $a_{i}$ are only to indicate their different attitudes, and they do not have to be too specific. The experiments are carried out by changing the value of inequity aversion parameters of FLSP1, $b_{1}$ increases from 0 to 1 , which corresponds to different degrees of FLSP1' inequity aversion, from fair-neutral to extremely inequity aversion. The experimental results are shown in Table 7 and Figures 13 and 14.

It can be seen from Table 7 that the three FLSPs pay more attention to their own revenue, and their distribution ratios are greater, when each FLSP pays different attention to its own revenue and all are not worthy of the average revenue. As FLSP1 pays more attention to its own revenue beyond the revenue itself, it has a great ratio in the supply chain's utility. At this time, $\lambda_{1}$ is relatively great and the effort level is relatively great, which can create more value-added. It can be seen from Figure 14 that $\lambda_{1}$ decreases with the increase of the inequity aversion's degree, $b_{1}$, while the ratios of other FLSPs increase when FLSP1 begins to pay attention to the fairness of revenue distribution. When $v_{i}$ is the same as the average, the distribution scheme is no longer affected by $b_{1} . v_{i}$ changes according to the change of its $\lambda_{i}$, while $\pi_{1}$ changes are the opposite from Figure 13. If LSI wants to get more revenue, it should cooperate with FLSPs who have inequity aversion. 
Table 7. Experimental results for Situation 1.

\begin{tabular}{cccccc}
\hline $\boldsymbol{b}_{1}$ & $\boldsymbol{\lambda}_{\boldsymbol{i}}(\boldsymbol{i}=1,2,3)$ & $\boldsymbol{U}$ & $\boldsymbol{\pi}_{1}$ & $\boldsymbol{V}$ & $\boldsymbol{v}_{\boldsymbol{i}}(\boldsymbol{i}=1,2,3)$ \\
\hline 0 & $0.9999,0.191,0.0002$ & 825.5984 & 325.198 & 500.4004 & $384.66,75.72,40.02$ \\
0.1 & $0.3988,0.5932,0.128$ & 813.8158 & 429.383 & 384.4328 & $138.47,187.33,58.63$ \\
0.2 & $0.3976,0.5941,0.1282$ & 813.7942 & 429.354 & 384.4402 & $138.13,187.64,58.67$ \\
0.3 & $0.3972,0.5944,0.1283$ & 813.7869 & 429.3411 & 384.4458 & $138.02,187.75,58.68$ \\
0.4 & $0.3970,0.5946,0.1284$ & 813.7833 & 429.3164 & 384.4669 & $137.96,187.81,58.7$ \\
0.5 & $0.3968,0.5947,0.1284$ & 813.7811 & 429.3282 & 384.453 & $137.9,187.85,58.7$ \\
0.6 & $0.3967,0.5948,0.1284$ & 813.7797 & 429.3202 & 384.4594 & $137.88,187.88,58.7$ \\
0.7 & $0.3967,0.5948,0.1284$ & 813.7787 & 429.3202 & 384.4584 & $137.88,187.88,58.7$ \\
0.8 & $0.3966,0.5949,0.1284$ & 813.7779 & 429.3123 & 384.4655 & $137.85,187.92,58.7$ \\
0.9 & $0.3966,0.5949,0.1284$ & 813.7773 & 429.3123 & 384.4649 & $137.85,187.92,58.7$ \\
1 & $0.3966,0.5949,0.1284$ & 813.7768 & 429.3123 & 384.4644 & $137.85,187.92,58.7$ \\
\hline
\end{tabular}

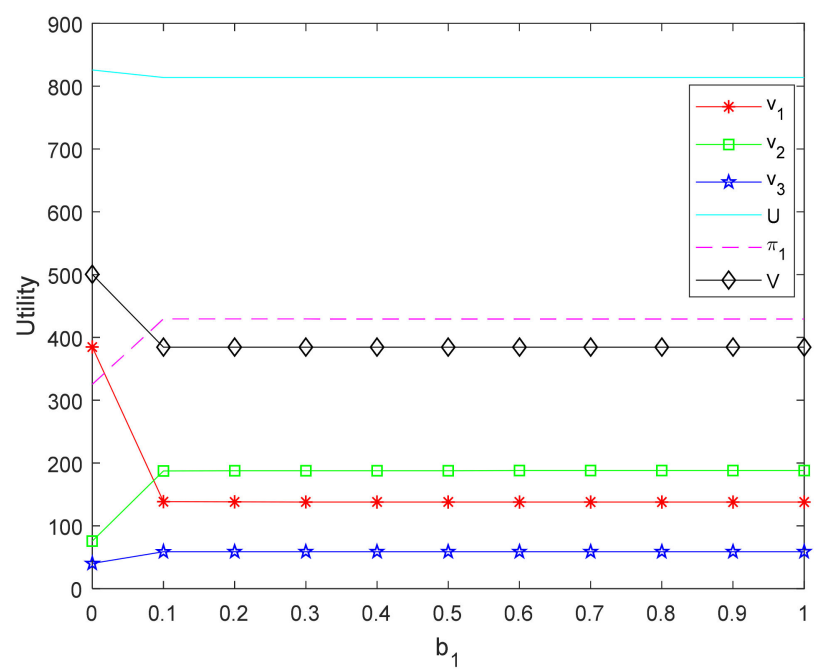

Figure 13. The effect of inequity aversion parameters on the utilities for Situation 1.

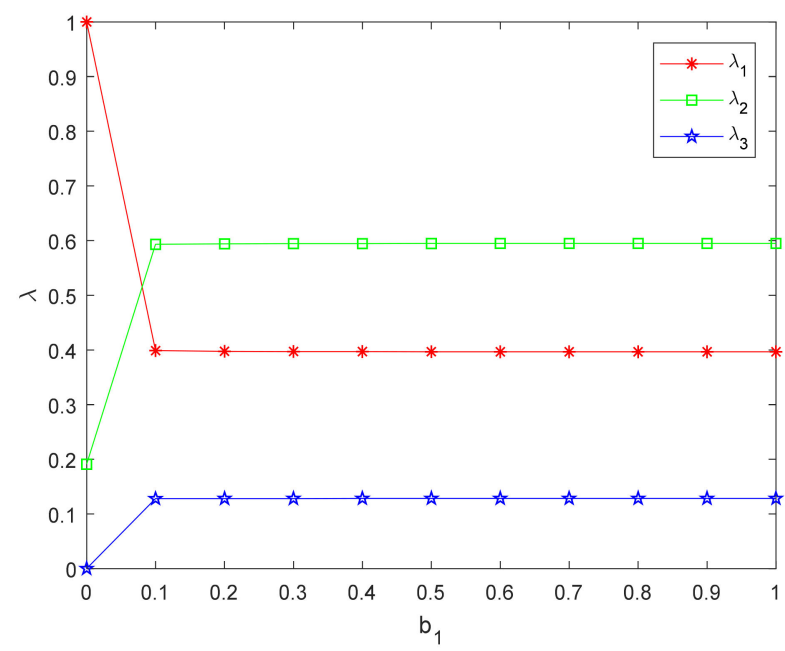

Figure 14. The effect of inequity aversion parameters on the distribution ratios for Situation 1.

Situation 2. Fair-neutral FLSPS account for the minority.

For situation 2, the inequity aversion parameters of the three FLSPs are $a_{1}=1.2$, $a_{2}=1, a_{3}=1$ and $b_{3}=0$, where only FLSP3 is fair-neutral. The experiments are carried out by changing the value of inequity aversion parameters of FLSP1 and FLSP2, 
$b_{1}$ and $b_{2}$, from 0 to 1 , respectively. The results of experiments are shown in Table 8 , Figures 15 and 16.

Table 8. Experimental results for Situation 2.

\begin{tabular}{cccccc}
\hline $\boldsymbol{b}_{1}, \boldsymbol{b}_{2}$ & $\boldsymbol{\lambda}_{\boldsymbol{i}}(\boldsymbol{i}=1,2,3)$ & $\boldsymbol{U}$ & $\boldsymbol{\pi}_{1}$ & $\boldsymbol{V}$ & $\boldsymbol{v}_{\boldsymbol{i}}(\boldsymbol{i}=1,2,3)$ \\
\hline 0 & $0.9999,0.191,0.0002$ & 825.60 & 325.20 & 500.40 & $384.66,75.72,40.02$ \\
0.1 & $0.3667,0.3651,0.3572$ & 810.91 & 457.02 & 353.89 & $129.77,118.45,105.67$ \\
0.2 & $0.3646,0.3640,0.3604$ & 810.84 & 457.02 & 353.82 & $129.21,118.17,106.44$ \\
0.3 & $0.3638,0.3637,0.3614$ & 810.82 & 457.04 & 353.78 & $129,118.1,106.68$ \\
0.4 & $0.3635,0.3635,0.3619$ & 810.81 & 457.05 & 353.77 & $128.92,118.05,106.8$ \\
0.5 & $0.3633,0.3634,0.3622$ & 810.80 & 457.05 & 353.76 & $128.86,118.02,106.87$ \\
0.6 & $0.3631,0.3633,0.3624$ & 810.80 & 457.06 & 353.74 & $128.81,118,106.93$ \\
0.7 & $0.3630,0.3633,0.3626$ & 810.80 & 457.05 & 353.75 & $128.78,118,106.97$ \\
0.8 & $0.3630,0.3632,0.3627$ & 810.79 & 457.05 & 353.75 & $128.78,117.97,107$ \\
0.9 & $0.3629,0.3632,0.3628$ & 810.79 & 457.05 & 353.75 & $128.76,117.97,107.02$ \\
1 & $0.3628,0.3632,0.3629$ & 810.79 & 457.05 & 353.75 & $128.73,117.97,107.04$ \\
\hline
\end{tabular}

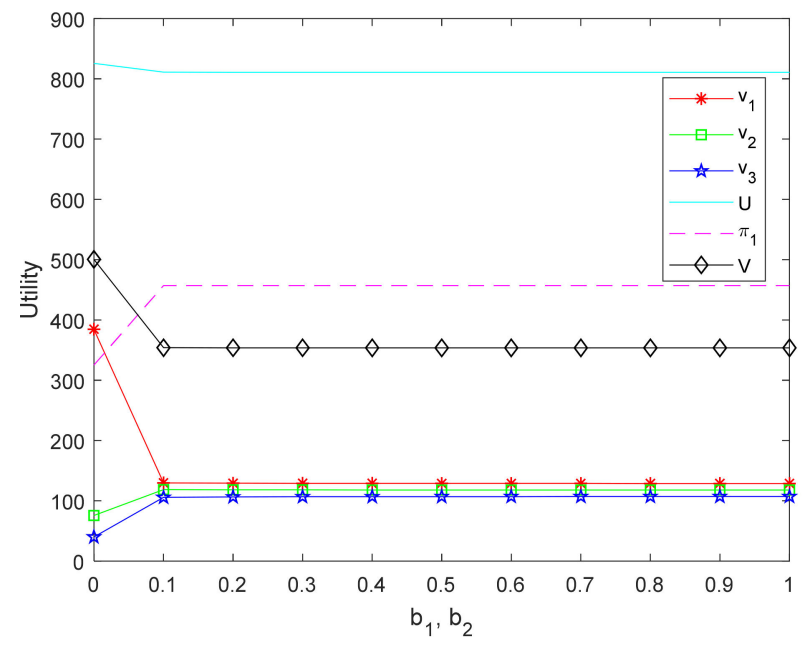

Figure 15. The effect of inequity aversion parameters on the utilities for Situation 2.

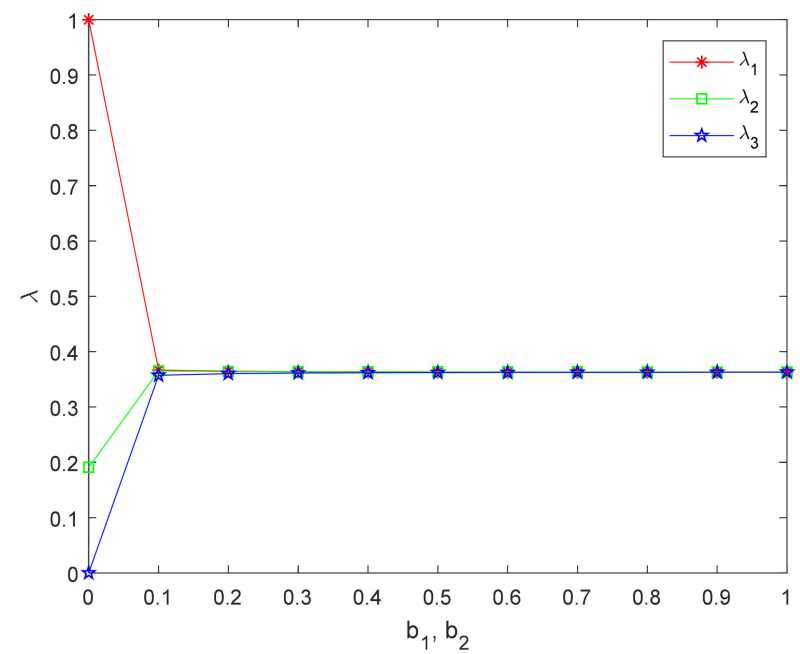

Figure 16. The effect of inequity aversion parameters on the distribution ratios for Situation 2.

It can be seen from Table 8 that FLSP2 begins to have disadvantageous inequity aversion, $\lambda_{2}$ and $v_{2}$ increase with the degree of inequity aversion, when the degree of members' inequity aversion is weak. From Figure 15, FLSP2 has advantageous inequity 
aversion while $v_{2}$ increases beyond the average level. As shown in Figure $16, \lambda_{1}$ decreases and $v_{1}$ decreases when the degree of inequity aversion increases. The changes in the remaining members are roughly the same as those in the case 1 and will not be repeated.

Compared with Situation 2 in Section 4.3.2, the improved BO model is used to increase the distribution ratio and utility of the disadvantaged FLSP when the degree of inequity aversion is strengthened and reduce the distribution ratio and make the revenue distribution fairer for an advantageous FLSP. It can be clearly seen that the improved BO model can better portray the inequity aversion of members and lead to a fairer revenue distribution plan.

(2) Extremely inequity aversion FLSPs among members

Situation 3. Extremely inequity aversion FLSPs account for the majority.

For situation 3, the inequity aversion parameters of the three FLSPs are $a_{1}=1.2$, $a_{2}=1, a_{3}=1, b_{i}=1, i=2,3$, where FLSP2 and FLSP3 are extremely inequity aversion. The experiments are carried out by changing the value of inequity aversion parameters of FLSP1, $b_{1}$ increases from 0 to 1 . The results of experiments are shown in Table 9 and Figures 17 and 18.

Table 9. Experimental results for Situation 3.

\begin{tabular}{cccccc}
\hline $\boldsymbol{b}_{1}$ & $\boldsymbol{\lambda}_{\boldsymbol{i}}(\boldsymbol{i}=1,2,3)$ & $\boldsymbol{U}$ & $\boldsymbol{\pi}_{1}$ & $\boldsymbol{V}$ & $\boldsymbol{v}_{\boldsymbol{i}}(\boldsymbol{i}=1,2,3)$ \\
\hline 0 & $0.3631,0.3627,0.3631$ & 810.79 & 457.05 & 353.75 & $128.83,117.84,107.08$ \\
0.1 & $0.3629,0.3628,0.3631$ & 810.79 & 457.06 & 353.72 & $128.77,117.87,107.09$ \\
0.2 & $0.3629,0.3628,0.3632$ & 810.79 & 457.05 & 353.74 & $128.77,117.86,107.11$ \\
0.3 & $0.3628,0.3629,0.3632$ & 810.79 & 457.05 & 353.74 & $128.74,117.89,107.11$ \\
0.4 & $0.3628,0.3629,0.3632$ & 810.79 & 457.05 & 353.74 & $128.74,117.89,107.11$ \\
0.5 & $0.3627,0.3629,0.3632$ & 810.79 & 457.06 & 353.72 & $128.71,117.9,107.11$ \\
0.6 & $0.3627,0.3629,0.3633$ & 810.78 & 457.05 & 353.74 & $128.71,117.89,107.14$ \\
0.7 & $0.3627,0.3629,0.3633$ & 810.78 & 457.05 & 353.74 & $128.71,117.89,107.14$ \\
0.8 & $0.3627,0.3629,0.3633$ & 810.78 & 457.05 & 353.74 & $128.71,117.89,107.14$ \\
0.9 & $0.3626,0.3630,0.3633$ & 810.78 & 457.05 & 353.74 & $128.68,117.92,107.14$ \\
1 & $0.3626,0.3630,0.3633$ & 810.78 & 457.05 & 353.74 & $128.68,117.92,107.14$ \\
\hline
\end{tabular}

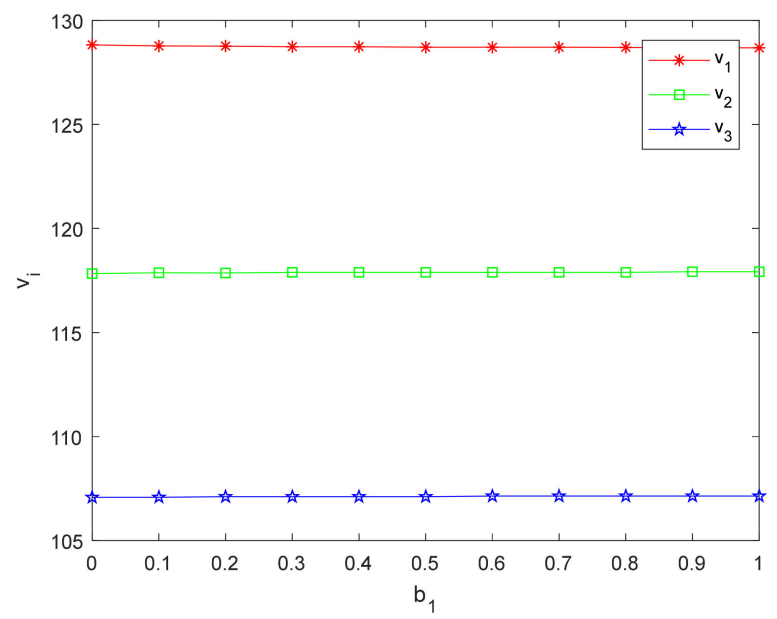

Figure 17. The effect of inequity aversion parameters on $v_{i}(i=1,2,3)$ for Situation 3. 


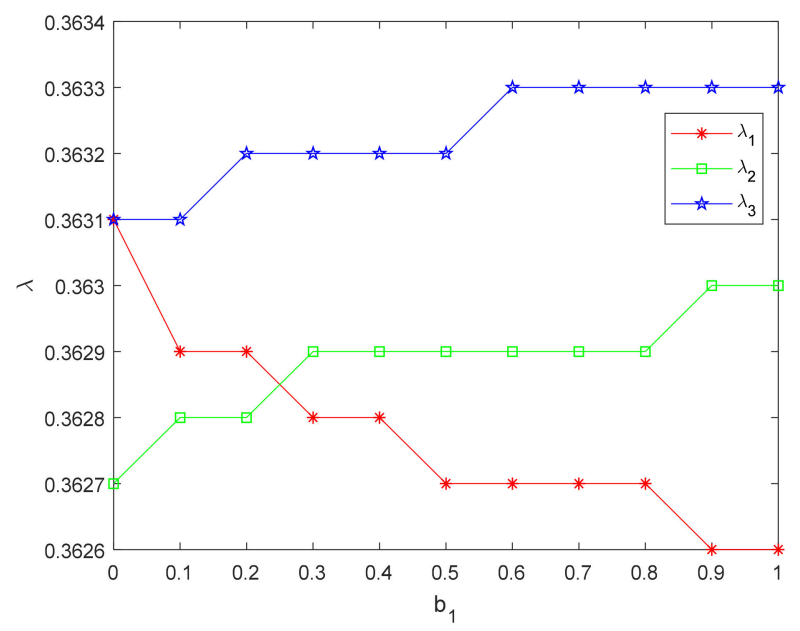

Figure 18. The effect of inequity aversion parameters on the distribution ratios for Situation 3.

It can be seen from Table 9 and Figure 17 the distribution ratios of the three FLSPs are similar, and the utility changes are small when the members with extremely inequity aversion are in majority. Figure 18 indicates that the FLSP1's distribution ratio, $\lambda_{1}$ decreases and the distribution ratios of other FLSPs increases, which is consistent with the trend of the previous two cases, when the advantageous FLSP1 inequity aversion becomes stronger. This is because more members pay attention to the fairness of distribution. In order to reduce the negative utility caused by inequity aversion, all FLSPs have similar distribution ratios and their profits are roughly the same as shown in Figures 17 and 18. In this case, the utility of LSI does not change much.

Compared with situation 3 in Section 4.3.2, with the original model, the ratio of members with extremely inequity aversion is extremely low, and the ratio of members with weak degrees of inequity aversion is high. With the improved BO model, the ratio of members who are extremely inequity aversion is appropriate, and the profit are the same as the average. For the FLSP with advantageous position, when its degree of inequity aversion is strengthened, its distribution ratio is reduced, and the distribution ratio of members who are extremely inequity aversion is increased, so that the distribution of revenue is fairer.

Situation 4. Extremely inequity aversion FLSPS account for the minority.

For situation 4 , the inequity aversion parameters of the three FLSPs are $a_{1}=1.2$, $a_{2}=1, a_{3}=1, b_{3}=1$, respectively, where FLSP3 is extremely inequity aversion. The experiments are carried out by changing the value of inequity aversion parameters of FLSP1 and FLSP2, $b_{1}$ and $b_{2}$, from 0 to 1 , respectively. The results of experiments are shown in Table 10, Figures 19 and 20.

Table 10. Experimental results for Situation 4.

\begin{tabular}{cccccc}
\hline $\boldsymbol{b}_{1}, \boldsymbol{b}_{2}$ & $\boldsymbol{\lambda}_{\boldsymbol{i}}(\boldsymbol{i}=1,2,3)$ & $\boldsymbol{U}$ & $\boldsymbol{\pi}_{1}$ & $\boldsymbol{V}$ & $\boldsymbol{v}_{\boldsymbol{i}}(\boldsymbol{i}=1,2,3)$ \\
\hline 0 & $0.5987,0.1226,0.3981$ & 813.85 & 428.48 & 385.37 & $206.89,63.54,114.94$ \\
0.1 & $0.3636,0.3621,0.3632$ & 810.80 & 457.05 & 353.75 & $128.97,117.68,107.11$ \\
0.2 & $0.3631,0.3626,0.3632$ & 810.79 & 457.05 & 353.74 & $128.82,117.81,107.11$ \\
0.3 & $0.3629,0.3627,0.3632$ & 810.79 & 457.06 & 353.72 & $128.77,117.84,107.11$ \\
0.4 & $0.3628,0.3628,0.3632$ & 810.79 & 457.06 & 353.72 & $128.74,117.87,107.11$ \\
0.5 & $0.3628,0.3629,0.3632$ & 810.79 & 457.05 & 353.74 & $128.74,117.89,107.11$ \\
0.6 & $0.3627,0.3629,0.3633$ & 810.78 & 457.05 & 353.74 & $128.71,117.89,107.14$ \\
0.7 & $0.3627,0.3629,0.3633$ & 810.78 & 457.05 & 353.74 & $128.71,117.89,107.14$ \\
0.8 & $0.3627,0.3629,0.3633$ & 810.78 & 457.05 & 353.74 & $128.71,117.89,107.14$ \\
0.9 & $0.3626,0.3629,0.3633$ & 810.78 & 457.06 & 353.72 & $128.68,117.9,107.14$ \\
1 & $0.3626,0.3630,0.3633$ & 810.78 & 457.05 & 353.74 & $128.68,117.92,107.14$ \\
\hline
\end{tabular}




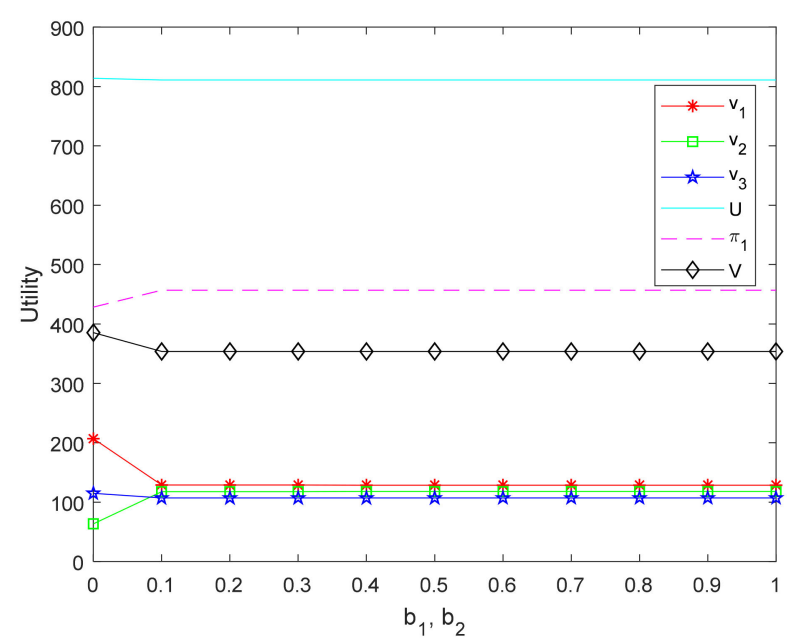

Figure 19. The effect of inequity aversion parameters on the utilities for Situation 4.

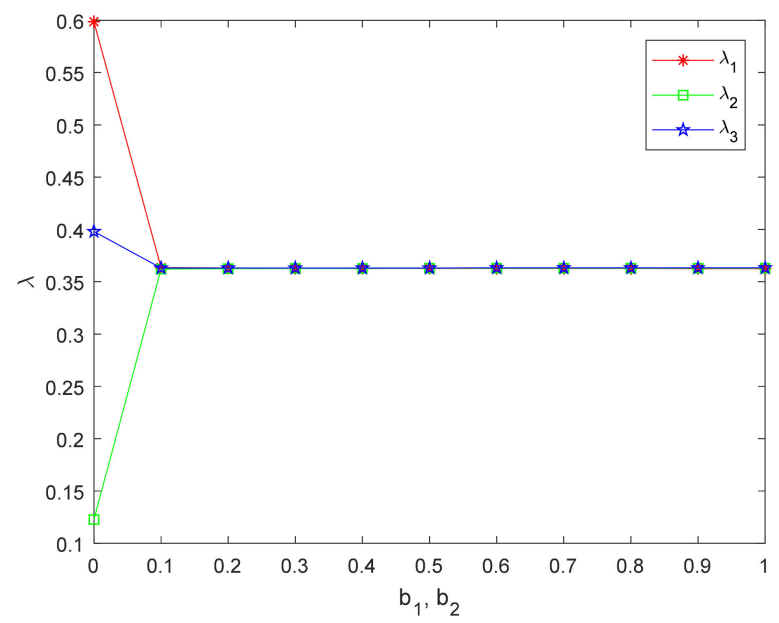

Figure 20. The effect of inequity aversion parameters on the distribution ratios for Situation 4 .

It can be seen from Table 10 and Figures 19 and 20 that situation 4 is roughly the same as situation 1 and situation 2 when member with extreme inequity aversion is the minority. However, FLSP3 is more concerned about the distribution fairness, and FLSP2 is less concerned with its own revenue than FLSP1, and FLSP1 is less inequity averse than FLSP2 at the beginning. As can be seen from situation 1, FLSP1 has an advantage in the whole. Therefore, as described in Figure 20, FLSP2 has the lowest distribution ratio and FLSP1 has the highest distribution ratio. Similar to situation 2, FLSP2 is below average, $\lambda_{2}$ increases with its disadvantageous inequity aversion, $b_{2}$, in Figure 20, and $v_{1}$ is higher than the average in Figure 19. $\lambda_{1}$ decreases with its advantageous inequity aversion. Figure 20 demonstrates that the distribution ratio is no longer affected by the degree of inequity aversion, while the members' revenues are almost the same.

Compared with Situation 4 in Section 4.3.2, with the original model, the ratio of members who are extremely inequity aversion is extremely low. With the improved BO model, the ratio of members who are extremely inequity aversion is appropriate, and the profit is the same as the average. For the disadvantageous FLSP, when its degree of inequity aversion is strengthened, the ratio of its distribution is appropriately increased to increase its utility. For the advantageous FLSP, reduce the distribution ratio and make the revenue distribution fairer.

(3) Experimental summary

Comparing the utility of supply chain and the profit of LSI in the four situations, Figure 21 shows that the supply chain has the greatest utility when all members are fair- 
neutral. As can be seen from Figures 21 and 22, the smaller $U$ are, but the greater $\pi_{1}$ are, when the more members pay attention to the fairness of distribution and the stronger the degree of inequity aversion is. This is because when FLSP focuses on the distribution of fairness, it will have a negative effect whether it is below or above the average. This indicates that the distribution ratios agreed between LSI and the three FLSPs should be similar to seek a fairer trade, and LSI has to work harder to get more revenue.

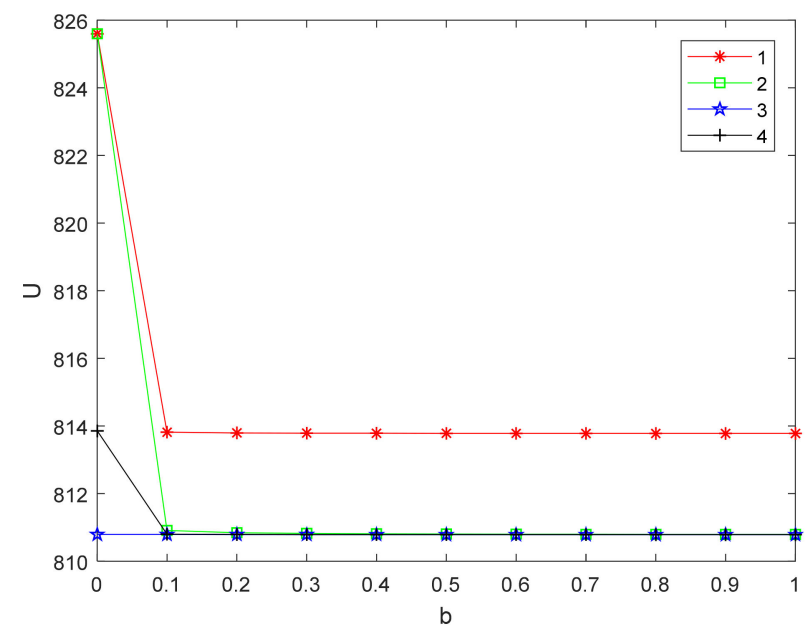

Figure 21. Comparison of supply chain's utility in four situations.

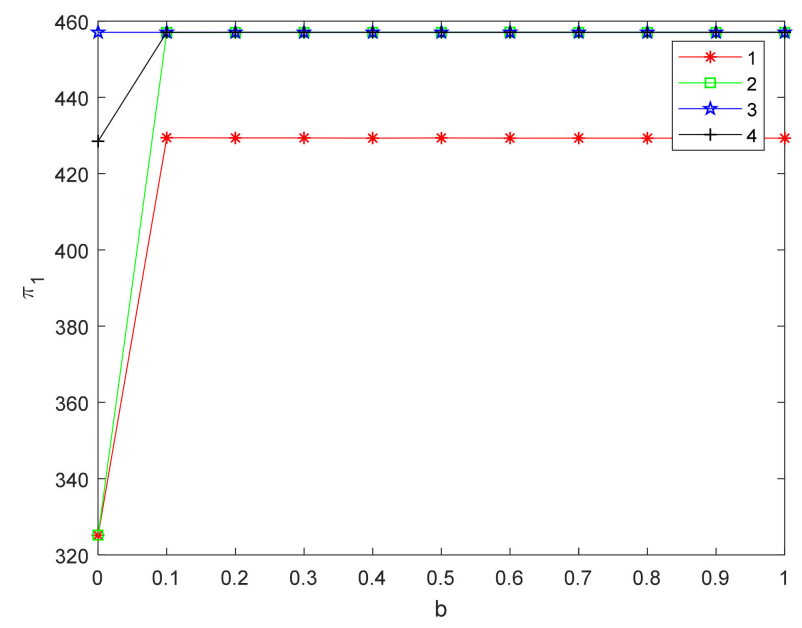

Figure 22. Comparison of LSI's profits in four situations.

Compared with the four situations in Section 4.3 above, the experimental results in this section are obviously different. Applying the improved BO model, there is no unreasonable situation in which the ratio of revenue distribution is lower and the utility is increased, when the FLSP has disadvantageous inequity aversion. The improved BO model can successfully describe the advantageous inequity aversion and disadvantageous inequity aversion of FLSP. Applying the improved BO model, the revenue distribution plan is fairer, more reasonable and more realistic. The improved BO model is suitable for situations where the specific information of peer members is not fully known, but the industry average is known, and $\phi$ can be adjusted according to the capabilities of the company.

\subsubsection{Influence of Relative Fairness Revenue Coefficient on Revenue Distribution}

In order to study the influence of the relative fairness revenue coefficient of FLSPs on the distribution scheme, the following experiment was conducted. There are two cases, 
(1) the members' relative fairness revenue coefficients are the same and (2) the members' relative fairness revenue coefficients are different. The initial data of the case is the same as in Section 4.3.1. To avoid the influence of the inequity aversion degree of members affecting the parameter analysis, the inequity aversion of the three FLSPs are the same, and the parameters are set, $a_{i}=1,(i=1,2,3)$ and $b_{i}=0.1,(i=1,2,3)$.

(1) Case 1: Members with the same relative fairness revenue coefficients

The relative fairness revenue coefficients of the three FLSPs are the same, since the strengths of the three FLSPs are similar, $\phi_{i}(1,2,3)$ is from 0.9 to 1.1 according to papers by Yang et al. (2013) [51], Katok et al. (2014) [31] and Wang et al. (2016) [48]. The results are shown in Table 11 and Figures 23 and 24.

Table 11. The results for the same relative fairness revenue coefficients.

\begin{tabular}{cccccc}
\hline$\phi_{\boldsymbol{i}}(\boldsymbol{i}=1,2,3)$ & $\lambda_{\boldsymbol{i}}(\boldsymbol{i}=1,2,3)$ & $\boldsymbol{U}$ & $\boldsymbol{\pi}_{1}$ & $\boldsymbol{V}$ & $\boldsymbol{v}_{\boldsymbol{i}}(\boldsymbol{i}=1,2,3)$ \\
\hline 0.9 & $0.0229,0.0229,0.0229$ & 772.34 & 644.62 & 127.72 & $42.57,42.57,42.57$ \\
0.95 & $0.1347,0.1348,0.1348$ & 779.02 & 583.68 & 195.34 & $65.11,65.12,65.11$ \\
0.96 & $0.1549,0.1549,0.1550$ & 780.27 & 572.62 & 207.66 & $69.23,69.22,69.21$ \\
0.97 & $0.1720,0.1721,0.1722$ & 781.35 & 563.18 & 218.17 & $72.73,72.72,72.72$ \\
0.98 & $0.1850,0.1851,0.1852$ & 782.18 & 556.02 & 226.16 & $75.39,75.39,75.38$ \\
0.99 & $0.1932,0.1933,0.1934$ & 782.70 & 551.50 & 231.21 & $77.08,77.07,77.06$ \\
1 & $0.1959,0.1961,0.1962$ & 782.88 & 549.97 & 232.91 & $77.64,77.64,77.63$ \\
1.01 & $0.1932,0.1933,0.1934$ & 782.70 & 551.50 & 231.21 & $77.09,77.07,77.05$ \\
1.02 & $0.1850,0.1851,0.1852$ & 782.18 & 556.02 & 226.16 & $75.39,75.39,75.38$ \\
1.03 & $0.1720,0.1721,0.1722$ & 781.35 & 563.18 & 218.17 & $72.73,72.72,72.72$ \\
1.04 & $0.1549,0.1549,0.1550$ & 780.27 & 572.62 & 207.66 & $69.23,69.22,69.21$ \\
1.05 & $0.1347,0.1348,0.1348$ & 779.02 & 583.68 & 195.34 & $65.11,65.12,65.11$ \\
1.1 & $0.0229,0.0229,0.0229$ & 772.34 & 644.62 & 127.72 & $42.57,42.57,42.57$ \\
\hline
\end{tabular}

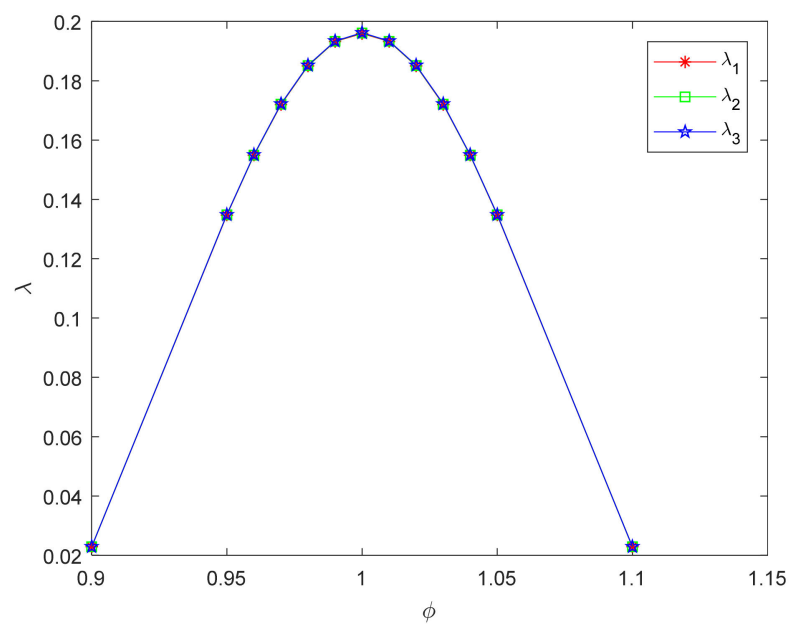

Figure 23. The distribution for the same relative fairness revenue coefficients. 


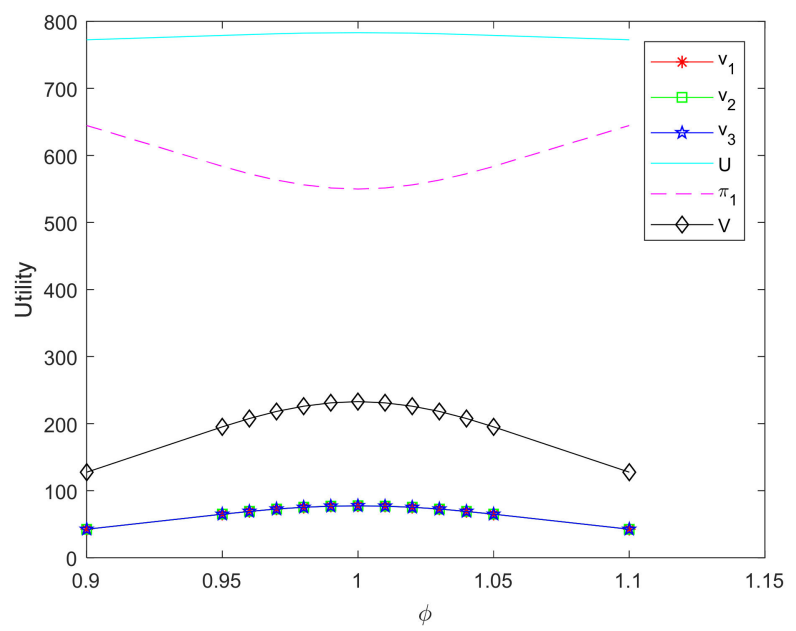

Figure 24. Variety of the utilities.

It can be seen from Table 11 and Figure 23 that the relative revenue coefficient $\phi=1$ makes the FLSP member distribution ratio the highest when the relative fairness revenue coefficients of the three FLSPs are the same. At this time, $v_{i}, V$ and $U$ are the highest in Figure 24. Figure 24 also indicates that $v_{i}$ and $U$ will decrease when the relative fairness revenue coefficient $\phi$ increases or decreases.

(2) Case 2: Members with different relative fairness revenue coefficients

The relative fairness revenue coefficients of the three FLSPs are different, $\phi_{1}$ from 0.9 to $1.1, \phi_{2}=0.95<1$, which means that the strength of the FLSP 2 is lower than the average, and $\phi_{3}=1.02>1$, which means that the strength of the FLSP 3 is higher than the average [31]. The selection of member whose $\phi_{i}$ is changed is random, and the values of $\phi_{2}$ and $\phi_{3}$ are set only to express the difference in FLSPs' strength, which will not affect the final conclusion [52-54]. The results are shown in Table 12 and Figures 25 and 26.

Table 12. The results for the different relative fairness revenue coefficients.

\begin{tabular}{cccccc}
\hline$\phi_{1}$ & $\boldsymbol{\lambda}_{\boldsymbol{i}}(\boldsymbol{i}=1,2,3)$ & $\boldsymbol{U}$ & $\boldsymbol{\pi}_{1}$ & $\boldsymbol{V}$ & $\boldsymbol{v}_{\boldsymbol{i}}(\boldsymbol{i}=1,2,3)$ \\
\hline 0.9 & $0.1299,0.1458,0.1675$ & 779.83 & 576.43 & 203.40 & $63.93,67.34,72.13$ \\
0.95 & $0.1687,0.1688,0.1920$ & 781.63 & 560.68 & 220.95 & $71.94,71.93,77.08$ \\
0.96 & $0.1753,0.1720,0.1955$ & 781.91 & 558.25 & 223.66 & $73.32,72.57,77.77$ \\
0.97 & $0.1814,0.1747,0.1984$ & 782.16 & 556.11 & 226.05 & $74.61,73.1,78.35$ \\
0.98 & $0.1869,0.1768,0.2007$ & 782.37 & 554.29 & 228.08 & $75.78,73.51,78.8$ \\
0.99 & $0.1920,0.1783,0.2024$ & 782.55 & 552.76 & 229.79 & $76.86,73.8,79.13$ \\
1 & $0.1964,0.1793,0.2035$ & 782.69 & 551.56 & 231.12 & $77.81,73.98,79.33$ \\
1.01 & $0.2003,0.1796,0.2040$ & 782.79 & 550.69 & 232.09 & $78.66,74.03,79.41$ \\
1.02 & $0.2035,0.1794,0.2038$ & 782.85 & 550.17 & 232.68 & $79.36,73.97,79.35$ \\
1.03 & $0.2061,0.1785,0.2030$ & 782.86 & 549.99 & 232.88 & $79.94,73.77,79.16$ \\
1.04 & $0.2081,0.1771,0.2015$ & 782.84 & 550.14 & 232.70 & $80.4,73.48,78.83$ \\
1.05 & $0.2094,0.1750,0.1995$ & 782.78 & 550.64 & 232.14 & $80.72,73.03,78.39$ \\
1.06 & $0.2063,0.1561,0.1801$ & 781.89 & 558.12 & 223.77 & $80.29,69.16,74.32$ \\
1.08 & $0.1299,0.1458,0.1675$ & 779.83 & 576.43 & 203.40 & $63.93,67.34,72.13$ \\
1.1 & $0.1687,0.1688,0.1920$ & 781.63 & 560.68 & 220.95 & $71.94,71.93,77.08$ \\
\hline
\end{tabular}




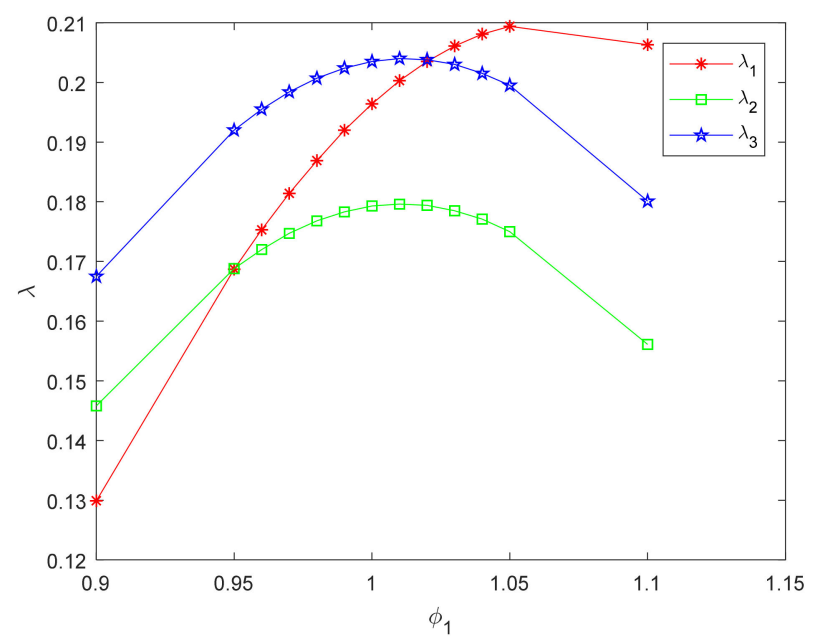

Figure 25. The distribution for the different relative fairness revenue coefficients.

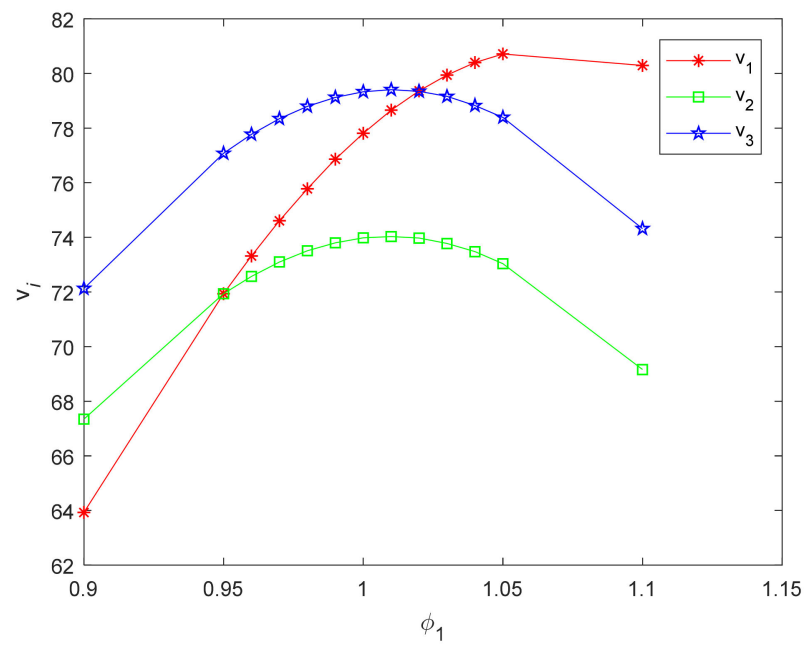

Figure 26. The $v_{i}$ for the different relative fairness revenue coefficients.

As can be seen from Table 12 and Figure 25, the distribution ratio of FLSP1 is lower than that of other FLSPs, $\lambda_{1}<\lambda_{2}<\lambda_{3}$, when $\phi_{1}<\phi_{2}<\phi_{3}$. With increases of $\phi_{1}, \lambda_{i}$ increases gradually, which is shown in Figure 25. FLSP1 and FLSP2 have the same revenue distribution ratio, which is smaller than the distribution ratio of FLSP3, $\lambda_{1} \approx \lambda_{2}<\lambda_{3}$ when $\phi_{1}=\phi_{2}<\phi_{3}$. The distribution ratio of FLSP1 is higher than other FLSPs, $\lambda_{1}>\lambda_{3}>\lambda_{2}$ when $\phi_{1}>\phi_{3}>\phi_{2}$. It can be concluded that the higher the relative fairness revenue coefficient of the FLSP is, the higher the distribution ratio is in the peer FLSPs. Figure 26 shows that the trend of the utility of FLSP is the same as the distribution ratio.

Comparing Figure 23 with Figure 25, it can be seen that $\phi$ that can make the ratio of member greatest have a deviation when the members have different relative fairness revenue coefficients. This is because the benchmark for comparison with the average level increases when a member's relative fairness revenue coefficient increases. LSI increases the distribution ratio and compensates for the inequity negative utility resulting from comparison.

(3) Experimental summary

Comparing the utility of the two types of experiments, it can be seen from Figures 27 and $28 U$ and $V$ of case 1 are equal to that of case 2 when $\phi_{1}=0.9858$ and $\phi_{1}=1.007$; when $0.9858<\phi_{1}<1.007, U$ and $V$ of case 1 are greater than that of case 2, where the differences between the $\phi_{i}$ of the FLSPs in Case 2 is small; when $0.9<\phi_{1}<0.9858$ and $\phi_{1}>1.007, U$ and $V$ of case 1 are smaller than that of case 2 , where 
the differences between the $\phi_{i}$ of the FLSPs in Case 2 is great. Figure 29 shows that the comparison result of $\pi_{1}$ in both cases is contrary to the comparisons of $U$ and $V$. $\phi_{i}$ denotes the degree of FLSP $i$ 's perceived relative advantage against the peers and the status of FLSP in the peers, and depends on the factors such as the fixed cost, efficiency and innovation capability of the enterprise, etc. Specifically, the larger the FLSP $i$ 's perceived relative advantage against the peers is, the stronger the strength of FLSP among their peers is, the bigger the $\phi_{i}$ will be. The greater the difference in the $\phi_{i}$ between FLSPs is, the greater the gap in the strength of FLSP is. If LSI only pursues to maximize its own interests, she can choose to cooperate with FLSPs with the same strength and whose strength is greater or lesser than average. When LSI cooperates with FLSPs with large differences in strength, she should give more powerful FLSPs higher distribution ratios to encourage them to create more value and reduce the ratios of weaker FLSPs.

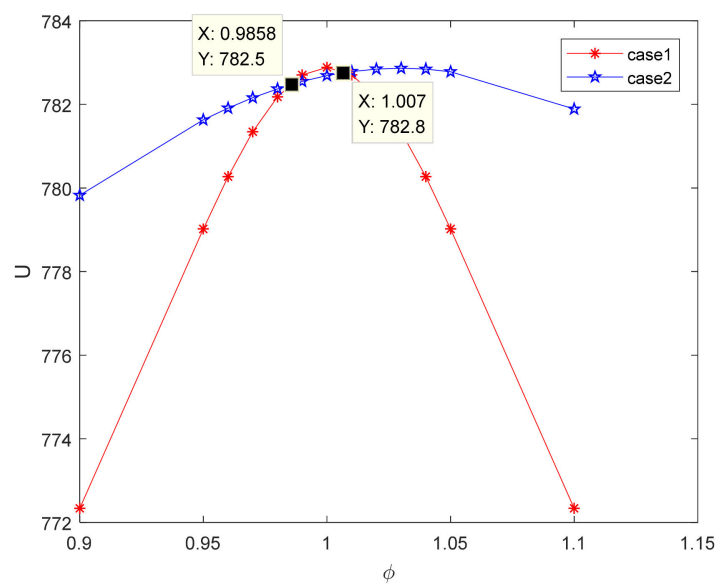

Figure 27. Comparison of the utility of the supply chain in two cases.

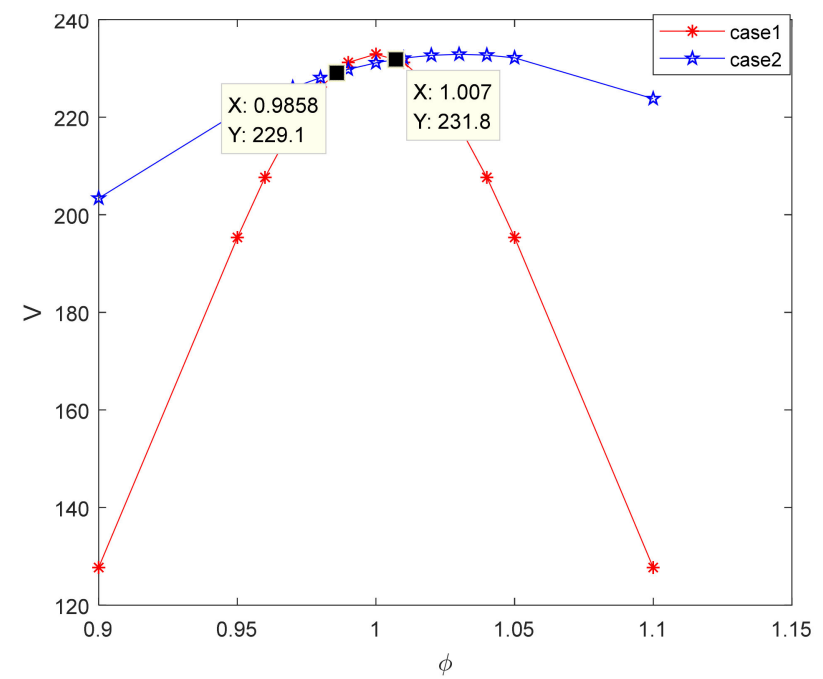

Figure 28. Comparison of the FLSPs' total utility in two cases. 


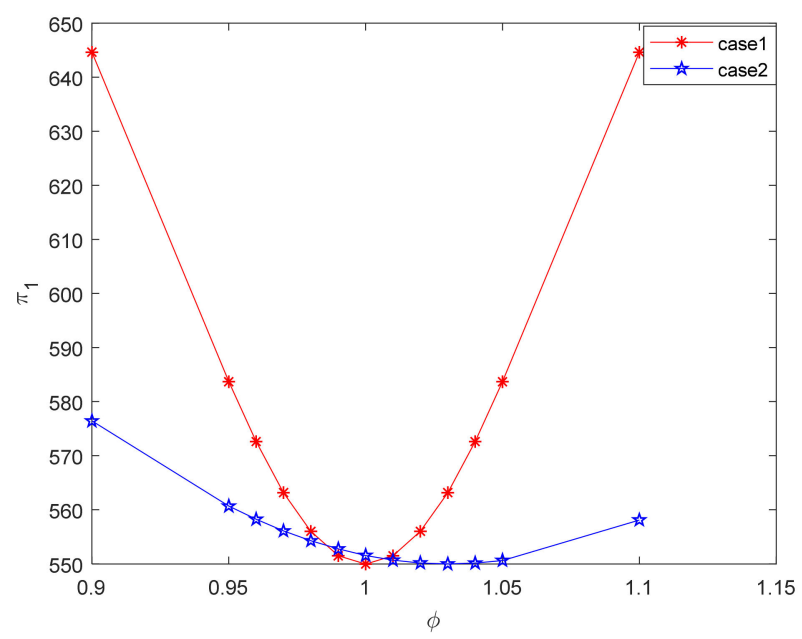

Figure 29. Comparison of LSI's revenue in two cases.

\section{Conclusions and Future Research}

In this paper, fairness preference is introduced into the study of revenue distribution in an LSSC consisting of one LSI and multiple FLSPs. The original BO model cannot describe the disadvantageous inequity aversion of the actors. Therefore, an improved original $\mathrm{BO}$ model is proposed to more fully characterize the peer-induced fairness preference of the FLSPs. In addition, the influence of FLSP's inequity aversion degree and the number of FLSP members with inequity aversion on revenue distribution are studied in the numerical simulation.

There are three main conclusions. First, the inequity aversion of FLSP affects the revenue distribution of the supply chain and the cooperation strategy of each member in LSSC are shown. Compared with the distribution plan when members are fair-neutral, there are significant differences in the supply chain's revenue distribution plan when FLSP has inequity aversion. The inequity aversion of FLSP affects the utility of its own, LSI and the supply chain. Second, the analysis also shows that the utility of FLSP decreases with the degree of its advantageous inequity aversion and increases with the degree of disadvantageous inequity aversion. Moreover, the more FLSP members with inequity aversion, the higher the utility of LSI, the lower the FLSPs' total utility and the supply chain. For LSI, she should choose FLSPs with weaker inequity aversion, and ensure that the revenue distribution is relatively fair, so as to reduce the loss caused by FLSP's inequity aversion. Finally, another interesting finding shows that the distribution ratio of FLSP increases with its relative fairness revenue coefficient among the peers of FLSPs. Moreover, when the difference in the relative fairness revenue coefficient of FLSP is small, the utility of the supply chain is large.

Enterprises or decision makers can learn from the major findings of this paper and use the specific suggestions in their operations. For example, when an LSI selects FLSP, the degree of inequity aversion of the FLSP should be fully considered, which will affect the utility of LSI and the entire supply chain; when an LSI selects multiple FLSPs, especially a large number of FLSPs, the FLSPs with weaker inequity aversion could be a good option to choose.

This paper still has some drawbacks. For example, only the FLSP's inequity aversion is considered. In the future, LSI's inequity aversion and the inequity aversion of both also should be considered. In addition, LSI is assumed in a dominant position. It would be interesting to explore the impact of both dominant and inequity aversion on the revenue distribution. 
Author Contributions: Conceptualization, F.L.; methodology, H.B.; formal analysis, S.W.; investigation, Z.D.; data curation, L.W.; writing-original draft preparation, L.W.; writing-review and editing, F.L.; project administration, F.L.; funding acquisition, F.L and H.B. All authors have read and agreed to the published version of the manuscript.

Funding: This work was funded by the National Key R\&D Program of China under Grant No. 2020YFB1712802, the National Science Foundation of China under Grant No. 71401027, the Humanities and Social Sciences funds for Hebei Universities under Grant No. SQ202002.

Institutional Review Board Statement: Not applicable.

Informed Consent Statement: Not applicable.

Data Availability Statement: Not applicable.

Conflicts of Interest: The authors declare no conflict of interest.

\section{References}

1. Tian, Y. Supplier Selection in Constructing Logistics Service Supply Chain. Syst. Eng. Theory Pract. 2003, 23, 49-53.

2. Choy, K.; Li, C.; So, S.; Lau, H.; Kwok, S.K.; Leung, D. Managing uncertainty in logistics service supply chain. Int. J. Risk Assess. Manag. 2007, 7, 19-43. [CrossRef]

3. Xie, C.; Anumba, C.J.; Lee, T.R.; Liu, W.H.; Xu, X.C.; Ren, Z.X.; Peng, Y. An emergency order distribution model based on multi-provider in two-echelon logistics service supply chain. Supply Chain Manag. 2011, 16, 391-400.

4. Lim, W.S. A lemons market? An incentive scheme to induce truth-telling in third party logistics providers. Eur. J. Oper. Res. 2000, 125, 519-525. [CrossRef]

5. Chen, J.H.; Wang, Y.; Sun, L.Y. Research on the Profit Distribution Gaming of Virtual Enterprise. Oper. Res. Manag. Sci. 2002, $11,11-16$.

6. Messick, D.M.; Sentis, K.P. Fairness and preference. J. Exp. Soc. Psychol. 1979, 15, 418-434. [CrossRef]

7. Cappelen, A.W.; Sørensen, E.Ø.; Tungodden, B. Responsibility for what? Fairness and individual responsibility. Eur. Econ. Rev. 2010, 54, 429-441. [CrossRef]

8. Nian, Z.; Bin, L.; Kun, W.; Mengxue, W. Game Models for Closed-Supply Chain with Different Competition-Cooperation Relationships under Fairness Preference. Complexity 2020, 2020, 6793216. [CrossRef]

9. Han, J.; Jia, M.; Wu, G.; Yang, H. Strategic Interaction Between the Government and the Private Sector in PPP Projects Incorporating the Fairness Preference. IEEE Access 2020, 8, 37621-37631. [CrossRef]

10. Werner, G.; Schmittberger, R.; Schwarze, B. An experimental analysis of ultimatum bargaining. J. Econ. Behav. Organ. 1982, 3, 267-388.

11. Gordon, B.; Katrine, V. Peer Effects in Program Participation. Am. Econ. Rev. 2014, 104, 2049-2074.

12. Li, K.J.; Jain, S. Behavior-Based Pricing: An Analysis of the Impact of Peer-Induced Fairness. Manag. Sci. 2015, 62, $2705-2721$. [CrossRef]

13. Celentani, M.; Loveira, R. A simple explanation of the relative performance evaluation puzzle. Rev. Econ. Dyn. 2006, 9, 525-540. [CrossRef]

14. Bolton, G.E.; Ockenfels, A. ERC: A Theory of Equity, Reciprocity, and Competition. Am. Econ. Rev. 2000, 90, 166-193. [CrossRef]

15. Samuelson, P.A. Altruism as a Problem Involving Group Versus Individual Selection in Economics and Biology. Am. Econ. Rev. 1993, 83, 143-148.

16. Sen, A. Rationality and Social Choice. Am. Econ. Rev. 1995, 85, 1-24.

17. Kreps, D.; Milgrom, P.; Roberts, J.; Wilson, R. Rational Cooperation in the Finitely Repeated Pisoner's Dilemma. J. Econ. Theory 1993, 27, 245-252. [CrossRef]

18. Falk, A.; Fehr, E.; Fischbacher, U. Testing theories of fairness-Intentions matter. Games Econ. Behav. 2008, 62, 287-303. [CrossRef]

19. Camerer, C.F.; Thaler, R.H. Anomalies: Ultimatums, Dictators and Manners. J. Econ. Perspect. 1995, 9, 209-219. [CrossRef]

20. Casal, S.; Güth, W.; Jia, M.; Ploner, M. Would you mind if I get more? An experimental study of the envy game. J. Econ. Behav. Organ. 2012, 84, 857-865. [CrossRef]

21. BäKer, A.; Güth, W.; Pull, K.; Stadler, M. The willingness to pay for partial vs. universal equality. J. Behav. Exp. Econ. 2015, 56, 55-61. [CrossRef]

22. Rabin, M. Incorporating Fairness into Game Theory and Economics. Am. Econ. Rev. 1993, 83, 1281-1302.

23. Dufwenberg, M.; Kirchsteiger, G. A theory of sequential reciprocity. Games Econ. Behav. 2004, 47, 268-298. [CrossRef]

24. Fehr, E.; Schmidt, K.M. A Theory of Fairness, Competition, and Cooperation. Q. J. Econ. 1999, 114, 817-868. [CrossRef]

25. Loch, C.H.; Wu, Y. Social Preferences and Supply Chain Performance: An Experimental Study. Manag. Sci. 2008, 54, 1835-1849. [CrossRef]

26. Pavlov, V.; Katok, E. Fairness and Coordination Failures in Supply Chain Contracts; Social Science Electronic Publishing: Rochester, NY, USA, 2015.

27. Katok, E.; Pavlov, V. Fairness in supply chain contracts: A laboratory study. J. Oper. Manag. 2013, 31, 129-137. [CrossRef] 
28. Qin, F.; Mai, F.; Fry, M.J.; Raturi, A. Supply-Chain Performance Anomalies: Fairness Concerns under Private Cost Information. Eur. J. Oper. Res. 2016, 252, 170-182. [CrossRef]

29. Cui, T.H.; Raju, J.S.; Zhang, Z.J. Fairness and Channel Coordination. Manag. Sci. 2007, 53, 1303-1314.

30. Caliskandemirag, O.; Chen, Y.; Li, J. Channel coordination under fairness concerns and nonlinear demand. Eur. J. Oper. Res. 2010, 207, 1321-1326. [CrossRef]

31. Katok, E.; Olsen, T.; Pavlov, V. Wholesale Pricing under Mild and Privately Known Concerns for Fairness. Prod. Oper. Manag. 2014, 23, 285-302. [CrossRef]

32. Teck, H.H.; Su, X.M.; Wu, Y.Z. Distributional and Peer-Induced Fairness in Supply Chain Contract Design. Prod. Oper. Manag. 2014, 23, 161-175.

33. Nie, T.; Du, S. Dual-fairness supply chain with quantity discount contracts. Eur. J. Oper. Res. 2016, 258, 491-500. [CrossRef]

34. Liu, W.; Wang, D.; Shen, X.; Yan, X.; Wei, W. The impacts of distributional and peer-induced fairness concerns on the decisionmaking of order allocation in logistics service supply chain. Transp. Res. Part E Logist. Transp. Rev. 2018, 116, 102-122. [CrossRef]

35. Jaber, M.Y.; Osman, I.H. Coordinating a two-level supply chain with delay in payments and profit sharing. Comput. Ind. Eng. 2006, 50, 385-400. [CrossRef]

36. Zhang, Z.Y.; Fu, D.X.; Zhou, Q. Optimal Decisions of a Green Supply Chain under the Joint Action of Fairness Preference and Subsidy to the Manufacturer. Discret. Dyn. Nat. Soc. 2020, 9610503, 1-18. [CrossRef]

37. Cachon, G.P.; Lariviere, M.A. Supply Chain Coordination with Revenue-Sharing Contracts: Strengths and Limitations. Manag. Sci. 2005, 51, 30-44. [CrossRef]

38. Chauhan, S.S.; Proth, J.M. Analysis of a supply chain partnership with revenue sharing. Int. J. Prod. Econ. 2005, 97, 44-51. [CrossRef]

39. Zhang, W.G.; Fu, J.; Li, H.; Xu, W. Coordination of supply chain with a revenue-sharing contract under demand disruptions when retailers compete. Int. J. Prod. Econ. 2012, 138, 68-75. [CrossRef]

40. Pan, K.; Lai, K.K.; Leung, C.H.S.; Di, X. Revenue-sharing versus wholesale price mechanisms under different channel power structures. Eur. J. Oper. Res. 2010, 203, 532-538. [CrossRef]

41. Li, Q.H.; Li, B. Dual-Channel Supply Chain Equilibrium Problems Regarding Retail Services and Fairness Concerns. Appl. Math. Model. 2016, 40, 7349-7367. [CrossRef]

42. Karakostas, A.; Sonntag, A.; Zizzo, D.J. Contract Choice: Efficiency and Fairness in Revenue Sharing Contracts. Scand. J. Econ. 2017, 119, 962-986. [CrossRef]

43. Zhijie, S.; Ying, Z.; Jianmin, Y. Closed-loop outsourcing logistics supply chain coordination management based on the profitsharing contract. In Proceedings of the 2009 International Conference on Management Science and Engineering-16th Annual Conference Proceedings, ICMSE, Moscow, Russia, 14-16 September 2009; Volume 2009, pp. 601-606.

44. Liu, W.H.; Xu, X.C.; Kouhpaenejad, A. Deterministic approach to the fairest revenue-sharing coefficient in logistics service supply chain under the stochastic demand condition. Comput. Ind. Eng. 2013, 66, 41-52. [CrossRef]

45. Wang, Y.; Ma, X.; Liu, M.; Gong, K.; Liu, Y.; Xu, M.; Wang, Y. Cooperation and Profit Allocation in Two-echelon Logistics Joint Distribution Network Optimization. Appl. Soft. Comput. 2017, 56, 143-157. [CrossRef]

46. Zeng, M.; Lin, H. Profit Allocation of E-Commerce Logistics Enterprise Alliance Based on Revised Shapely: Under the Circumstance of Warehouse Overload. Manag. Sci. Eng. 2016, 10, 1-7.

47. Gan, M.; Yang, S.; Li, D.D.; Wang, M.F.; Chen, S.; Xie, R.H.; Liu, J.Y. A Novel Intensive Distribution Logistics Network Design and Profit Allocation Problem considering Sharing Economy. Complexity 2018, 2018, 1-15. [CrossRef]

48. Wang, N.; Fan, Z.P.; Wang, X. Channel Coordination in Logistics Service Supply Chain considering Fairness. Math. Probl. Eng. 2016, 2016, 1-15. [CrossRef]

49. Liu, W.; Wang, S.; Zhu, D.L.; Di, W.; Shen, X. Order allocation of logistics service supply chain with fairness concern and demand updating: Model analysis and empirical examination. Ann. Oper. Res. 2018, 268, 177-213. [CrossRef]

50. Liu, W.; Zhao, X.; Wu, R. Revenue-Sharing Contract Models for Logistics Service Supply Chains with Mass Customization Service. Math. Probl. Eng. 2015, 2015, 9-11. [CrossRef]

51. Fehr, E.; Fischbacher, U. Why Social Preferences Matter-The Impact of Non-Selfish Motives on Competition. Econ. J. 2002, 112, 1-33. [CrossRef]

52. Yang, J.; Xie, J.; Deng, X.; Xiong, H. Cooperative advertising in a distribution channel with fairness concerns. Eur. J. Oper. Res. 2013, 227, 401-407. [CrossRef]

53. Mohammad, Y.; Parinaz, A. Suppliers' coalition strategy for green-Resilient supply chain network design. J. Ind. Prod. Eng. 2021, 38, 197-212.

54. Ghahremani Nahr, J.; Pasandideh, S.H.; Niaki, S.T. A robust optimization approach for multi-objective, multi-product, multiperiod, closed-loop green supply chain network designs under uncertainty and discount. J. Ind. Prod. Eng. 2020, 37, 1-22. [CrossRef] 